\title{
An overview of different methods of myocardial protection currently employed peri-transplantation
}

\author{
Sanjeet Singh Avtaar Singh ${ }^{1,3}$, Sudeep Das De ${ }^{1}$, Cristiano Spadaccio', Colin Berry ${ }^{2,3}$, Nawwar Al-Attar ${ }^{1}$ \\ ${ }^{I}$ Department of Cardiothoracic Surgery, Golden Jubilee National Hospital, Glasgow G81 4DY, UK. \\ ${ }^{2}$ Department of Cardiology, Golden Jubilee National Hospital, Glasgow G81 4DY, UK. \\ ${ }^{3}$ Institute of Cardiovascular \& Medical Sciences, University of Glasgow, Glasgow G81 4DY, UK.
}

Correspondence to: Mr. Sanjeet Singh Avtaar Singh, Department of Cardiothoracic Surgery, Golden Jubilee National Hospital, Glasgow G81 4DY, UK. E-mail: sanjeetsingh@nhs.net

How to cite this article: Singh SSA, Das De S, Spadaccio C, Berry C, Al-Attar N. An overview of different methods of myocardial protection currently employed peri-transplantation. Vessel Plus 2017;1:213-29.

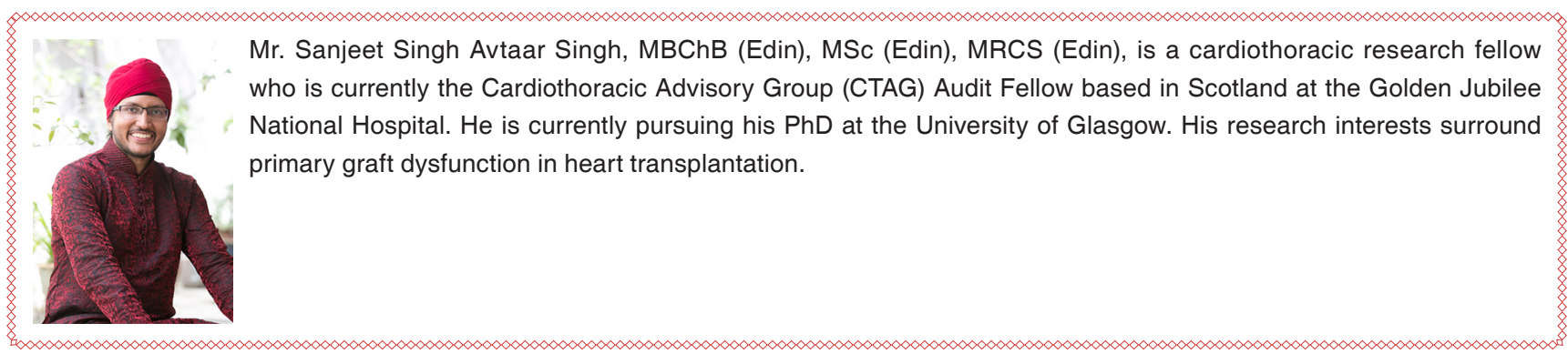

\section{Article history:}

Received: 26 Jul 2017

First Decision: 7 Sep 2017

Revised: 17 Sep 2017

Accepted: 20 Sep 2017

Published: 28 Dec 2017

\section{Key words:}

Myocardial protection, cardiac surgery, cardiac transplantation

\begin{abstract}
ABSTRAC T
Myocardial protection is integral to the functioning of hearts in day to day cardiac surgery. However, due to the longer ischaemic times, it becomes pivotal in the management of organs during transplantation. There are many different strategies employed to ensure diligent and judicious myocardial protection during donor management, transportation of the heart and the post-operative period. Given the limited supply of organs and the increasing waiting lists for heart transplants worldwide, it has become an area of renewed interest with many innovations and inventions using the principles of basic sciences to improve outcomes of transplanted hearts. The heart procurement process encompasses several of the different myocardial protection strategies in tandem to provide the greatest benefit to the recipients. This review looks at the different modalities employed, which include different types of cardioplegia, the role of biomarkers, the cutting-edge novel therapies, hormonal therapies and ischaemic conditioning strategies.
\end{abstract}

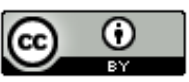

This is an open access article licensed under the terms of Creative Commons Attribution 4.0 International License (https://creativecommons.org/licenses/by/4.0/), which permits unrestricted use, distribution, and reproduction in any medium, as long as the original author is credited and the new creations are licensed under the identical terms.

For reprints contact: service@oaepublish.com

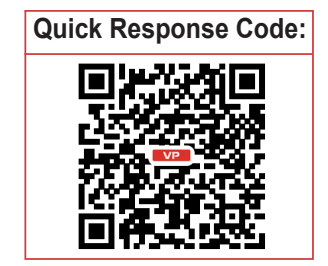

(C) The Author(s) 2017 


\section{INTRODUCTION}

Cardiac surgery is a rapidly evolving specialty when compared to other forms of surgery. In the 19th century, professor Theodor Billroth, one of the pioneers of modern abdominal surgery once stated: "A surgeon who tries to suture a heart wound deserves to lose the esteem of his colleagues" in $1896^{[1]}$. In 1951, Russian physiologist Vladimar Petrovich Demikhov performed the first thoracic transplants recorded. He transplanted the heart and lungs of a male dog into a 3-year-old female dog. The dog survived 6 days exhibiting normal behaviour but succumbed to respiratory complications. This was the first recorded history of any animal surviving any length of time with a transplanted heart supporting its circulation ${ }^{[2]}$.

Stanford University Medical Center led the field in cardiac transplantation. Norman Shumway from the University of Minnesota was well known for his work on myocardial protection. Along with Lillehei, they would later lead the team that refined the technique of orthotopic heart transplantation. They reported a series of orthotopic heart transplantations in dogs and perfected a method that had been use previously by Cass and Brock by preserving the recipient atrial cuffs $^{[3]}$. They had also first introduced the idea of cold cardioplegia. These experiments were successful but Shumway that host immunologic mechanisms were destroying the graft and survival could be prevented by addressing these ${ }^{[4]}$.

Shumway searched for biomarkers to monitor transplant rejection. Initial experiments with enzymes (hypertensin I) were unsuccessful. He settled on electrocardiography as a monitor but noted its limitations and pointed out that atrial fibrillation within 7-21 days of transplant was an early sign of rejection ${ }^{[5]}$. After working with transplant nephrologists, he assessed the potential benefits of immunosuppression (6-mercaptopurine, azathioprine, and prednisolone) and increased survival by up to 250 days in dogs receiving orthotopic transplants. Dr. Christiaan Barnard extended their pioneering work. Barnard undertook the first successful human-to-human heart transplant in December $1967^{[6]}$, before Shumway's group followed shortly afterwards in January 1968.

However, the initial reported 1-year survival was only $22 \%$, resulting in most centers abandoning this procedure $^{[7]}$. Shumway's group at Stanford along with other contemporaries (Cabrol's group at Paris, Lower's group at Virginia) persevered and following introduction of cyclosporine, 1-year survival increased to approximately $80 \%$ by the 80 s.

The number of heart transplants performed worldwide continued to increase until the shortage of donors in the 1990s became a limiting factor ${ }^{[8]}$. In 2005, almost half $(48 \%)$ of patients had spent at least 2 years on the heart transplant waiting list worldwide ${ }^{[9]}$ leading to challenging decisions about the eligibility of donor hearts. Abuanzeh et al. ${ }^{[10]}$ described steps utilized by their retrieval team to optimize donors. This was included standardizing protocols which includes insertion of a pulmonary artery catheter and performance of cardiac output studies, weaning other vasopressors and commencing arginine vasopressin, and administration of hormone replacement. This included tri-iodothyronine, methylprednisolone and insulin. They managed to retrieve 14 additional hearts in that time frame (56\% of the borderline hearts) after aggressive donor management and optimization ${ }^{[10]}$.

Despite recent advances, myocardial protection during heart transplantation remains a challenging avenue. With the increasing usage of borderline donor hearts as described, we review some of the myocardial protection strategies and potential markers for perioperative myocardial infarction.

\section{CARDIOPLEGIA}

Ringer first noted the relationship between potassium and sodium concentration and the heart rate in $1883^{[11]}$. Experimentations with potassium citrate were initially unsuccessful due to the excessive osmolality due to the high-concentration potassium citrate ${ }^{[12]}$. Most cardioplegic solutions today employ a more physiological osmolality and potassium concentration.

Cardioplegic solutions are defined as intracellular and extracellular solutions based on the concentrations of sodium and potassium ions. Extracellular solutions contain high levels of potassium, magnesium and sodium, while intracellular solutions contain low electrolyte levels. Intracellular solutions mimic the high potassium/low sodium conditions reducing potential concentration gradients across the plasma membrane, thereby halting potassium efflux. This reduction in membrane potential resting state prevents generation of action potentials. The function of the $\mathrm{Na}^{+} / \mathrm{K}^{+}$ ATPase channel is reduced in hypothermic conditions, therefore permitting the intracellular concentrations to persist ${ }^{[13]}$. Extracellular cardioplegia on the other hand works by preventing repolarization of myocytes. Potassium rich perfusate in the extracellular space reduces the membrane voltage difference causing 
depolarization. Intracellular calcium sequestration occurs via active transport across an ATP-dependent pump allowing relaxation of the myocardium in diastole. Repolarization however is prevented by the high potassium concentration of the cardioplegic solution. Both intracellular and extracellular cardioplegic solutions have similar long-term outcomes ${ }^{[14]}$.

Norman Shumway first noted the use of topical hypothermia to reduce myocardial metabolic requirements in 1960 when chemical cardioplegia fell out of favour ${ }^{[15]}$. Denton Cooley then attempted intermittent aortic occlusion and utilized Kay's work with intracoronary blood perfusion with cross clamp fibrillation ${ }^{[16-18]}$.

Clinical cardioplegia was reintroduced in the 1970 s by using a low-sodium solution by Bretschneider et al. ${ }^{[19]}$ with potassium chloride ${ }^{[20]}$ that was reported as safe and allowed safer aortic cross-clamping allowing cold crystalloid cardioplegic solutions to be in favour for general cardiac surgery. Blood was later introduced as medium for cardioplegia by Buckberg as it was later discovered that reperfusion injuries occurred in crystalloid cardioplegia due to the associated influence of calcium and oxygen as described by Buckberg ${ }^{[21]}$ and Hearse et al.. ${ }^{[22]}$. There are intracellular and extracellular types of crystalloid cardioplegia which have become the gold standard for cardiac preservation [Table 1] ${ }^{[23]}$.

\section{Histidine-tryptophan-ketoglutarate (custodiol/ bretschneider)}

Reichenspurner et al. ${ }^{[24]}$ studied the effect of histidinetryptophan-ketoglutarate (HTK) in a cohort of 600 (524 male:76 female) patients undergoing heart transplantation over a 10-year period (1981-1991). They reported good results provided the ischaemic times were less than $4 \mathrm{~h}$.

Sung et al. ${ }^{[25]}$ compared Bretscheinder's HTK solution (18 patients) and cold blood cardioplegia (CBC) (49 patients) for myocardial protection in donor heart preservation. Cold HTK solution was infused at low perfusion pressure after procurement and the donor heart was placed in a sterile bag containing HTK solution. The CBC group heart was placed in St Thomas' Hospital (StH). The heart was covered with ice-cold saline for topical cooling and packed in a container filled with ice. Two patients $(11.1 \%)$ in the HTK group died within 30 days of surgery due to right heart failure and pneumonia with septic shock. There were 4 deaths $(8.2 \%)$ in the CBC group due to acute rejection $(n=2)$, right heart failure and pneumonia with septic shock. There was no statistically significant difference between thebypass time, ischaemic time short term outcomes, creatine kinase/CKMB/troponin I values, length of ICU stay, and hospital stay between

Table 1: Comparison of cardioplegic solutions contents

\begin{tabular}{|c|c|c|c|c|c|}
\hline & HTK $^{[15]}$ & $\begin{array}{l}\text { University of } \\
\text { Wisconsin }^{[16]}\end{array}$ & Celsior $^{[14]}$ & Eurocollins $^{[17]}$ & $\begin{array}{l}\text { St Thomas's } \\
\text { Solution }^{[18]}\end{array}$ \\
\hline Intracellular/extracellular & Extracellular & Intracellular & Extracellular & Intracellular & Extracellular \\
\hline $\mathrm{Na}^{+}$ & 10 & 25 & 100 & 10 & 120 \\
\hline $\mathrm{K}^{+}$ & 10 & 120 & 15 & 115 & 16 \\
\hline $\mathrm{Ca}^{2+}$ & 0.015 & 0 & 0.25 & 0 & 1.2 \\
\hline $\mathrm{Mg}^{2+}$ & 4 & 5 & 13 & 0 & 16 \\
\hline $\mathrm{Cl}^{-}$ & 50 & 20 & 0 & 15 & 160 \\
\hline Glucose & - & 0 & 0 & 180 & 0 \\
\hline Others & $\alpha-K G$ & Adenosine & 0 & & 0 \\
\hline Glucose & 0 & 0 & 0 & 195 & 0 \\
\hline \multicolumn{6}{|l|}{ Impermeant/colloid } \\
\hline Hydroxyl-Ethyl Starch (g/L) & 0 & 0 & 50 & 0 & 0 \\
\hline Lactobionate & 0 & 0 & 100 & 80 & 0 \\
\hline Mannitol & 30 & 0 & & 60 & 0 \\
\hline Raffinose & 0 & 0 & 30 & 0 & 0 \\
\hline \multicolumn{6}{|l|}{ Buffer } \\
\hline Phosphate & 0 & 25 & 0 & 100 & 0 \\
\hline Bicarbonate & 0 & 0 & 0 & 10 & 10 \\
\hline Histidine & 180 & 0 & 30 & & 00 \\
\hline Osmolarity (mOsm/L) & 310 & 330 & 320 & 375 & 320 \\
\hline \multicolumn{6}{|l|}{ Anti-oxidants } \\
\hline Glutothione & 0 & 2 & 3 & 0 & 0 \\
\hline Allopurinol & 0 & 1 & 0 & 0 & 0 \\
\hline Tryptophan & 2 & 0 & 0 & 0 & 0 \\
\hline
\end{tabular}

All units expressed in $\mathrm{mmol} / \mathrm{L}$ unless otherwise indicated 
the 2 groups. There was however a higher inotropic score in the HTK group at $24 \mathrm{~h}(P=0.03)$. Multivariate analysis revealed a significantly reduced bypasstime in the HTK group $(P=0.002)$. They concluded that HTK was superior due to the reduced pumping time albeit with a higher post-operative inotrope score. A single dose of HTK provided similar myocardial protection as repeated doses of $C B C$ solution in donated hearts. Minami et al. ${ }^{[26]}$ noted an increment in troponin and CK-MB levels if the ischaemic times were $>4 \mathrm{~h}$ using HTK solution but concluded that it was still within acceptable limits when compared to other crystalloid cardioplegias CK-MB $25 \mathrm{IU}$ and troponin I $21 \mathrm{pg} / \mathrm{mL}$, with ischaemic time of $263 \mathrm{~min}$ ).

HTK is an intracellular type of cardioplegic solution. It lowers concentrations of sodium and calcium thereby inducing cardiac arrest by deprivation of extracellular sodium thus preventing depolarisation of the action potential. Calcium channels open leading to increased cytosolic calcium and potentially aggravating cellular injury, indirectly reducing the calcium concentration. Histidine in the HTK solution, acts as a buffer enhancing the efficiency of anaerobic glycolysis. This has been quoted by several sources to be its primary advantage, with its buffering capacity allowing effective myocardial preservation. The Ketoglutarate ( $\alpha-K G)$ component serves as a high energy ATP provider during reperfusion. Tryptophan stabilises the cell membranes. Mannitol, an osmotic diuretic is added to reduce cellular oedema as it has free radical scavenging properties thus reducing the extent of ischaemic injury ${ }^{[27]}$.

\section{St Thomas's solution}

St Thomas's solution ( $\mathrm{StH}$ ) is an extracellular type of cardioplegic solution that induces rapid cardiac arrest by high potassium and magnesium concentrations alongside the membrane stabilising effect of procaine ${ }^{[28]}$. Addition of a buffer and reduction of calcium concentrations resulted in the formation of No. 2 (Plegisol, Abbott Laboratories, North Chicago, III.). In a rat model, Plegisol was shown to be superior to its predecessor with lower rates of post-operative ventricular fibrillation, increased left ventricular pressure and recovery of aortic flow ${ }^{[29]}$. Addition of procaine in this solution reduces the incidence of postdeclamping ventricular fibrillation. Luciani et al. ${ }^{[30]}$ group performed a prospective single blinded randomised control trial comparing cold blood cardioplegia to StH (crystalloid cardioplegia). Spontaneous sinus rhythm was significantly higher in the blood cardioplegia group $(11 \%$ vs. $40 \%)(P=0.02)$ with a higher creatine kinase $(P=0.01)$ and CK-MB $(144 \pm 90$ IU vs. $102 \pm$ $59 \mathrm{IU})(P=0.06)$. They performed a follow up study 12 years later and revealed no difference in terms of mortality (46\% vs. $42 \%, P=0.7)$ and cause of death (chronic rejection: $50 \%$ vs. $50 \%$; neoplasia: $33 \%$ vs. $25 \%, P=0.8)$. Survival at 12 years was $50 \pm 12 \%$ vs. $52 \pm 11 \%(P=0.9)$. Follow-up echocardiogram showed similar mean left ventricular ejection fraction (LVEF; 47 $\pm 12 \%$ vs. $49 \pm 11 \%, P=0.7)$ and prevalence of LVEF < $35 \%(21 \%$ vs. $18 \%, P=0.8)$. The prevalence of chronic rejection was similar in both groups $(42 \%$ vs. $32 \%, P$ $=0.1$ ), but severe allograft vasculopathy was more prevalent in the St Thomas cardioplegia group $(64 \%$ vs. $17 \%, P=0.04)$. There were no other betweengroup differences ${ }^{[31]}$.

\section{Eurocollins}

Collins et al. ${ }^{[32]}$ designed an "intracellular" organ preservation solution and is credited to being one of the first solutions to attempt the advancement of organ preservation based on changes that occur during cell hypothermia. The predecessor to the Eurocollins solution, Collins solution, provided reliable preservation and was the organ preservation fluid of choice in abdominal organ transplantation especially renal preservation.

Collins solution has a high potassium content alongside a glucose osmotic barrier. Despite achieving relatively long storage times for abdominal organs, hearts were more susceptible to ischaemic injury and the low protective properties of glucose compounded by the acidotic conditions resulting from glucose conversion to lactate resulted in the addition of mannitol or sucrose instead of glucose as the impermeant ${ }^{[33]}$. Euro-Collins solution however fell out of favour due to the variability of recovery of hearts at non-uniform temperatures ${ }^{[34]}$.

\section{University of Wisconsin (Belzer UW/Viaspan)} University of Wisconsin Solution (UW) was formulated by James et al. ${ }^{[35]}$ in the late 1980 s as the preservation fluid of choice for pancreas preservation. Prior to its introduction, abdominal organs preserved in Collins solution would have limited ischaemic tolerance of about $8 \mathrm{~h}$. Belzer and Southard developed UW solution initially to prolong liver and pancreas preservation. Their initial experiments of canine pancreases were encouraging and used it for liver and kidneys with similarly encouraging results ${ }^{[36-38]}$.

UW solution became the "gold standard" of preservation fluids as it first highlighted the lack of equilibrium achieved by $\mathrm{Na}^{+} / \mathrm{K}^{+}$ratios during cold preservation ${ }^{[39]}$. It contains lactobionate and raffinose, which are metabolically inert, making it suitable for multiorgan usage. Both these substances which are osmotically active prevent organ oedema. Addition of adenosine provides precursor of an energy source (ATP). 
Allopurinol with glutathione act as antioxidants ${ }^{[40,41]}$. UW limited ischaemic damage from prolonged storage and improved myocardial function in the early posttransplant period, thus allowing transplantation of organs with ischaemic times $>300 \mathrm{~min}^{[42]}$. Jeevanandam et al. ${ }^{[43]}$ performed a study comparing University of Wisconsin solution with crystalloid cardioplegia to saline storage and noted a significant improvement in mean time from reperfusion to achieving a stable rhythm, need for intraoperative defibrillation, need for cardiac pacing and CK-MB release over $48 \mathrm{~h}$. They however also reported higher CK-MB levels (335 IU) post-operatively despite a relatively shorter ischaemic time of $153 \mathrm{~min}$ when compared to the HTK group of Minami's cohort ${ }^{[26]}$.

\section{Celsior}

$\mathrm{Dr}$ Menasche and colleagues developed Celsior solution $^{[44]}$. They utilised lactobionate and mannitol as impermeants. Celsior also uses histidine as a buffer and glutamate as an energy substance alongside magnesium to stabilise calcium levels. Unlike UW which has a high potassium content, Celsior had a lower potassium content and a high sodium concentration. In canine models, Celsior had a similar cardioprotective profile as UW. Higher concentrations of potassium results in increase coronary vascular resistance secondary to endothelial distension ${ }^{[45,46]}$. De Santo et al. ${ }^{[46]}$ compared the results of "high risk" grafts vs. "standard" grafts using Celsior. They followed up 200 consecutive heart recipients with 73 in the highrisk group (defined as 2 or more of the following: age $>45$, female, high pre-retrieval inotropic support, size mismatch $>20 \%$, and ischaemia time $>180 \mathrm{~min}$ ) and 127 in the standard group. There was no difference noted between the two groups in terms of 1-year mortality, hospital mortality, histological findings and patterns of enzyme release ${ }^{[4]]}$.

\section{Comparison of cardioplegic solutions}

Lee et al.[48] combined both the intracellular and extracellular cardioplegic solutions (HTK and $\mathrm{StH})$. In their cohort of 31 patients, they demonstrated noninferiority to other approaches. The theoretical benefits include the quick initial arrest from $\mathrm{StH}$ alongside the prolonged effect of HTK alongside its buffering mechanism. The effectiveness of HTK has resulted in lower CK and lactate dehydrogenase levels in nontransplant cardiac surgery [Table 2] ${ }^{[48,49]}$.

Comparisons between the different crystalloid cardioplegia solutions are difficult to extrapolate due to the lack of direct comparisons. Several smaller animal studies however do suggest potential superiority of HTK cardioplegia over the rest.

\section{BIOMARKERS}

Cardiac troponins have largely replaced cardiac muscle enzymes (CK-MB) for the diagnosis of myocardial infarction. Cardiac troponin T (cTnT) and troponin I (cTnl) are cardiac regulatory proteins that control the calcium mediated interaction between actin and myosin. cTnT is also expressed in small amounts in skeletal muscles as well. The role of post-operative troponin release as a prognostic factor for mid- and short-term all-cause mortality after adult cardiac surgery is accepted albeit cut-off values are difficult to establish due to the variety of timing of the Tn testing, Tn subunit and Tn assays ${ }^{[59]}$. Its prognostic value in a transplant setting however has not been clearly understood. CK-MB and troponin $\mathrm{I}$ are released immediately after transplantation and depends on myocardial ischaemic damage, which is related to ischaemic time ${ }^{[60]}$.

De Santo et al. ${ }^{[60]}$ investigated troponin release after cardiac transplantation. Data from 362 consecutive recipients were collated over 11 years. Target outcomes included factors determining troponin release, early graft failure, rise in creatinine and operative death. This study depicted the largest group of adult cardiac transplantation patients who had cTnl levels correlated with perioperative morbidity and mortality reported in the literature thus far. The pattern of troponin release observed was similar to that reported by Minami. cTnl release $>10 \mu \mathrm{g} / \mathrm{L}$ proved to be an independent predictor for early graft dysfunction which in turn was a determinant of hospital mortality. Factors that predicted this rise included previous cardiac surgery, left ventricular hypertrophy, increased ischaemic time and transplant status $2 \mathrm{~B}$. Troponin proteins are intracellular proteins released primarily from cardiac myocytes undergoing cellular necrosis. Perhaps surprisingly, ischaemia/reperfusion injury following cardiac transplantation may not cause cellular necrosis and occasionally troponin concentrations may not be increased ${ }^{[61]}$.

Brain natriuretic peptide (BNP) is actively synthesized and released from cardiac myocytes in response to ischaemia and inflammation ${ }^{[62]}$. It is not directly stimulated by surgical manipulation or cardiopulmonary bypass, hence its role as a biomarker for ischaemic reperfusion injury in non-transplant cardiac surgery to predict post-operative dysfunction ${ }^{[63,64]}$. Mcllroy et al. ${ }^{[65]}$ studied the role of BNP as marker for myocardial ischaemic reperfusion in 25 consecutive patients following cardiac transplantation. The median preoperative troponin-I concentrations were almost three-fold the upper limit of normal in both the donor and recipient. The donor BNP levels centred around 
Table 2: Comparison of studies comparing cardioplegic agents

\begin{tabular}{|c|c|c|c|c|c|c|}
\hline Study & $\begin{array}{l}\text { Year of } \\
\text { study }\end{array}$ & Type & Solution & Cases $(n)$ & Findings & Comment \\
\hline Vega et al. ${ }^{[50]}$ & 2001 & $\begin{array}{l}\text { Open Label RCT } \\
\text { (Humans) }\end{array}$ & $\begin{array}{l}\text { Celsior } v s . \\
\text { Standard of } \\
\text { care (UW, } \\
\text { STh, others) }\end{array}$ & $\begin{array}{l}\text { Celsior (64) } \\
\text { SOC (67) }\end{array}$ & $\begin{array}{c}\text { Fewer patients in the Celsior } \\
\text { group experienced at least } \\
\text { one cardiac-related serious } \\
\text { adverse event }\end{array}$ & $\begin{array}{l}\text { Younger recipients in } \\
\text { control group }\end{array}$ \\
\hline Wieselthaler et al. ${ }^{[51]}$ & 1999 & $\begin{array}{l}\text { Open Label RCT } \\
\text { (Humans) }\end{array}$ & $\begin{array}{l}\text { HTK vs. } \\
\text { Celsior }\end{array}$ & $\begin{array}{l}\text { HTK (24) } \\
\text { Celsior (24) }\end{array}$ & $\begin{array}{c}\text { Increased Ischaemic time } \\
\text { for HTK group ( } P \text {-values not } \\
\text { given) } \\
2 \text { cases of Acute graft failure } \\
\text { in HTK cohort }\end{array}$ & Similar outcomes \\
\hline Cannata et al. ${ }^{[52]}$ & 2012 & $\begin{array}{l}\text { Retrospective } \\
\text { cohort (humans) }\end{array}$ & $\begin{array}{l}\text { Celsior vs. } \\
\text { HTK vs. STh }\end{array}$ & $\begin{array}{l}\text { HTK (61) Celsior } \\
\text { (38) STh (34) }\end{array}$ & Similar outcomes & Similar outcomes \\
\hline George et al. ${ }^{[53]}$ & 2012 & $\begin{array}{l}\text { Retrospective } \\
\text { cohort }\end{array}$ & UW vs. Celsior & $\begin{array}{l}\text { UW (42) } \\
\text { Celsior (134) }\end{array}$ & $\begin{array}{l}\text { UW is associated with less } \\
\text { acute ischaemic necrosis } \\
\text { (on pathology) than CS }\end{array}$ & \\
\hline George et al..$^{[54]}$ & 2011 & $\begin{array}{l}\text { Retrospective } \\
\text { cohort }\end{array}$ & UW vs. Celsior & $\begin{array}{c}\text { UW }(3,107) \text { Celsior } \\
(1,803)\end{array}$ & $\begin{array}{l}\text { In high-risk allografts, } \\
\text { UW was associated with } \\
\text { improved survival }\end{array}$ & $\begin{array}{l}\text { UW recipient cohort } \\
\text { had significantly } \\
\text { better haemodynamic } \\
\text { readings pre- } \\
\text { operatively }\end{array}$ \\
\hline Kofler et al. ${ }^{[55]}$ & 2009 & $\begin{array}{l}\text { Retrospective } \\
\text { cohort } \\
\text { (humans) }\end{array}$ & UW vs. HTK & $\begin{array}{l}\text { UW (118) HTK } \\
\text { (222) }\end{array}$ & $\begin{array}{l}\text { UW demonstrated a } \\
\text { significantly better survival }\end{array}$ & $\begin{array}{l}\text { HTK group was } \\
\text { derived from historic } \\
\text { control }\end{array}$ \\
\hline Garlicki et al. ${ }^{[56]}$ & 1999 & $\begin{array}{l}\text { Retrospective } \\
\text { cohort }\end{array}$ & $\begin{array}{l}\text { UW vs. Celsior } \\
\text { vs. HTK }\end{array}$ & $\begin{array}{l}\text { UW (64) } \\
\text { CEL (28) } \\
\text { HTK (132) }\end{array}$ & HTK had highest mortality & $\begin{array}{c}\text { Statistical significance } \\
\text { uncertain as } P \text {-values } \\
\text { unavailable }\end{array}$ \\
\hline Lee et al. ${ }^{[57]}$ & 2011 & $\begin{array}{l}\text { Prospective } \\
\text { cohort } \\
\text { Lewis donor rat }\end{array}$ & $\begin{array}{l}\text { HTK vs. } \\
\text { Celsior }\end{array}$ & NA & $\begin{array}{l}\text { HTK = Significant reduction } \\
\text { in serum troponin I \& } \\
\text { creatine phosphokinase } \\
\text { HTK = reduction in } \\
\text { upregulation of mRNA for } \\
\text { interleukin- } 6 \text {, intercellular } \\
\text { adhesion molecule-1, and } \\
\text { tumor necrosis factor- } \alpha \text {, } \\
\text { fewer infiltrating cells, } \\
\text { less apoptosis, and less } \\
\text { phosphorylated adenosine } \\
\text { monophosphate-activated } \\
\text { protein kinase }\end{array}$ & $\begin{array}{l}\text { HTK- superior } \\
\text { protective effects } \\
\text { against ischemia- } \\
\text { reperfusion in older } \\
\text { donors }\end{array}$ \\
\hline Ackemann et al. ${ }^{[58]}$ & 2002 & $\begin{array}{l}\text { Prospective } \\
\text { cohort } \\
28 \text { to } 35 \mathrm{~kg} \text { adult } \\
\text { fox hound dogs }\end{array}$ & $\begin{array}{l}\text { HTK vs. } \\
\text { Celsior }\end{array}$ & $\begin{array}{c}19 \text { (HTK) vs. } 19 \\
\text { (Celsior) }\end{array}$ & $\begin{array}{c}\text { HTK = more ATP after } 8 \text { and } \\
12 \mathrm{~h} \text { of ischemia }\end{array}$ & $\begin{array}{l}\text { HTK = better LV } \\
\text { function, less prone to } \\
\text { arrhythmic events }\end{array}$ \\
\hline
\end{tabular}

NA: not applicable; LV: left ventricular; HTK: histidine-tryptophan-ketoglutarate

the upper limit of normal, while in recipients, it was the levels were all markedly elevated with greater heterogeneity. Posto-peratively, BNP had a moderate correlation with ischaemic time $(\rho=0.52, P=0.01)$, donor BNP ( $\rho=0.45, P=0.03$ ), and donor troponin-I $(\rho=0.49, P=0.01)$. The post-operative concentrations of BNP were significantly higher in patients requiring increasing doses of inotropic support. However, there was no correlation between post-operative troponin I and the measured parameters.

The role of microRNAs (miRNAs) as a biomarker for cardiac disease is rapidly expanding due to its rapid release kinetics, cardio-selectivity and plasma stability ${ }^{[66]}$. It negatively regulates gene expression by prohibiting complementary messenger RNAs (mRNAs) translation into functional proteins. Wang et al. ${ }^{[67]}$ attempted to monitor initial injury to the myocardium and post-operative recovery by detecting levels of circulating muscle-specific miRNAs in 7 consecutive patients. Fourteen controls were also included in their study. Samples were obtained at daily intervals post transplantation. They also collected cTnl levels. Their results showed significant correlation between miRNAs and $\mathrm{cTnl}(P<0.05)$ and the circulating concentrations of both proteins were strongly correlated with bypass time. Circulating miR-133b correlated well with parameters of heart function such as central venous. It also had strong correlations with ventilation time $(r>0.99, P<$ $0.001)$ and length of ICU stay $(r>0.92, P<0.05)$. They 
concluded that cardiac muscle specific miRNAs could detect early myocardial injury and possibly predict graft dysfunction and recovery post-operatively.

\section{NOVEL THERAPIES}

The current standard of care for organ preservation of hearts post explant is cold preservation (usually in an icebox). Perfusion of the heart with cold preservative solution is then followed by explantation and storage of the heart at $4{ }^{\circ} \mathrm{C}$. The choice of cardioplegic solution is primarily based on experience of individual centres. The generally acceptable time for cold preservation is about $4 \mathrm{~h}$ with ISHLT data suggesting that ischaemic times > $6 \mathrm{~h}$ associated with primary graft dysfunction ${ }^{[68]}$. One of the contributing factors to primary graft dysfunction may be suboptimal organ preservation alongside the role of ischaemia reperfusion injury.

Goldsmith et al. ${ }^{[69]}$ group analysed the potential benefits of reducing the ischaemic time (IT). They analysed survival rates beyond 20 years' post-transplantation. The study showed that median survival post-transplantation was between 10-11 years. Every additional hour of donor organ IT, conferred a $25 \%$ increased risk of death after heart transplantation in the first year after transplant, with a $5 \%$ increase thereafter $(P<0.001)$. On average, recipients surviving a decade post-transplantation could potentially gain 0.4 life-years if IT was reduced to $1 \mathrm{~h}$. This worked out to almost 3 life years saved if IT was reduced to $1 \mathrm{~h}$ if someone had IT $>6 \mathrm{~h}^{[69]}$.

To overcome this limitation, Hassanein et al. ${ }^{[0]}$ proposed the use of a makeshift continuous perfusion device to permit prolonged storage of allografts.

At $2 \mathrm{~h}$ of reperfusion, the hearts that were continuously perfused had higher LV generated pressures and lower lactate levels (myocardial acidosis) compared to the controls in cold storage. Based on Hassanein's findings, the Organ Care System (OCS), a continuous perfusion device developed by TransMedics, Inc., Andover, MA, USA, was then used in two phase 1 trials, the prospective multi-centre European trial to evaluate the safety and performance of the Organ Care System for heart transplants (PROTECT) trial based in Europe and the Prospective Multicentre Safety and Effectiveness Evaluation of the Organ Care System Device for Heart Use (PROCEED) trial based in the United States. The OCS consists of a miniature pulsatile pump with an inbuilt inline heater. It is also permits monitoring of cardiac output, coronary flow and blood pressure via the attached monitor. A specific perfusion solution consisting of part crystalloid, part glucose and amino acids, physiological extracellular electrolyte concentrations, free-radical scavengers, antibiotics, and calculated levels of catecholamines and insulin alongside oxygenated warm blood with a haematocrit of $20-25 \%$; thus simulating a more "physiological" environment ${ }^{[71]}$.

The PROTECT trial[72] was a prospective study of 20 patients who received donor hearts that had been maintained by the OCS in a perfused and physiologic beating state for a mean time of $3.7 \mathrm{~h}$. The graft survival rate of $100 \%$ at 30 days and the percentage of cardiac related complications was $23 \%$. Additionally, OCS was associated with earlier recovery with a shorted ventilation time and shorter ICU stay. The PROCEED ${ }^{[73]}$ trial was a 20 patient, single arm, nonrandomized, Food and Drug Administration approved safety and performance study. This study highlighted the importance of lactate concentration during OCS use. Hamed's group concluded that when using the OCS for donor heart maintenance, the final serum lactate concentrationis the most powerful predictor of graft failure post heart transplant with high sensitivity and specificity ${ }^{[74]}$.

PROCEED ${ }{ }^{[75]}$ was the first prospective, open-label, multicentre, randomised non-inferiority trial comparing OCS to current standard of care (cold hypothermic static preservation) at ten heart-transplant centres in the USA and Europe. Eligible adult heart-transplant candidates were randomly assigned (1:1) to receive donor hearts preserved with either the Organ Care System or standard cold storage. One hundred and thirty patients were recruited and randomised to Organ Care System group $(n=67)$ or the standard cold storage group $(n=63)$. The 30 -day patient and graft survival rates were $94 \%(n=63)$ in the Organ Care System group and $97 \%(n=61)$ in the standard of care $(P=0.45)$. Eight $(13 \%)$ patients in the Organ Care System group and $9(14 \%)$ patients in the standard cold storage group had cardiac-related serious adverse events. The results were consistent with noninferiority of OCS vs. standard of care in terms of short term outcomes. Donor hearts in the OCS group had a significantly longer preservation (out-of-body) time, but shorter cold ischemia time compared to standard of care. The longest preservation time with the OCS was $9 \mathrm{~h}$ and $7 \mathrm{~min}$ thought to be due to the extra time needed to instrument the donor heart into the Organ Care System circuit and optimise the perfusion characteristics.

Donation following cardiac death however is a new avenue which resulted in an increase of available organs. Initially used primarily for kidney transplantation, donor after circulatory death (DCD) was first split into four categories 
Table 3: Modified Maastricht Classification of DCD ${ }^{[76]}$

\begin{tabular}{ll}
\hline Classification & Descriptions \\
\hline I & Dead on arrival and have not been resuscitated \\
III & Unsuccessfully resuscitated \\
IV & $\begin{array}{l}\text { Typical controlled DCD, with planned cardiac } \\
\text { arrest }\end{array}$ \\
& $\begin{array}{l}\text { Planned DBD that suddenly arrest during or } \\
\text { after the brain death determination }\end{array}$ \\
\hline
\end{tabular}

DCD: donor after circulatory death; DBD: donations following brain death

by the Maastricht group [Table 3] ${ }^{[76]}$.

Of these, type I, II and IV are regarded uncontrolled DCD. For these donors, cardiopulmonary resuscitation is typically conducted until organ recovery procedures are employed.

lyer et al. ${ }^{[7]}$ conducted a porcine orthotopic heart transplant using a DCD asphyxia model. Following $30 \mathrm{~min}$ of warm ischaemia, the hearts were allocated to either OCS preservation of SOC with Celsior solution. Following preservation, the OCS group demonstrated acceptable lactate profiles and all hearts out of this group were successfully transplanted whereas none of the hearts in the SOC group could be weaned off bypass.

Dhital et al. ${ }^{[78]}$ then piloted the first case series of Maastrict group III DCD cardiac transplants at St Vincent's Hospital (Australia) using the OCS. The 3 recipients (2 men and 1 woman; mean age 52 years) received the transplants. After periods of warm ischaemia $<30 \mathrm{~min}$, ex-vivo perfusion was done with the OCS device to resuscitate, assess, and transport the donor hearts. Of these patients, 1 required mechanical circulatory support for $72 \mathrm{~h}$ postoperatively, with all 3 patients showing normal cardiac function within a week post-transplantation. Follow up data shows patients are still making a good recovery at 176, 91, and 77 days after transplantation.The cohort included a fourth donor, a trauma victim, who was excluded as the warm ischaemic time was $>30$ min (which did not meet the inclusion criteria).

DCD donation however was not pioneered by this group. In fact the first ever cardiac transplant by Barnard was a DCD heart. Boucek et al. ${ }^{[79]}$ highlighted the first case series of DCD donations in the paediatric population owing to the higher waiting list mortality compared to adults. They successfully performed 3 transplants in the paediatric population and found no late deaths (3.5 years post-operatively) with functional and immunologic outcomes similar to those of controls.

In March 2015, the first DCD heart transplant in Europe was performed at Papworth Hospital ${ }^{[80]}$. While it is quoted that this may potentially increase the donor pool by about $25 \%$ in the UK alone, several ethical issues arise from DCD heart procurement. These include the definition of death. While the needs and feelings of the donors and their families are noted, organ viability should be maintained and maximized. Organ donation in itself should not be the reason for donor death ${ }^{[81]}$.

Another point noted by the Australian group was the potential use of OCS for resuscitating marginal donors. An estimated $60 \%$ of hearts offered are rejected for transplantation and the introduction of OCS may therefore on paper at least, increase the number of suitable organs ${ }^{[82]}$.

\section{HORMONAL THERAPY}

As alluded to, the increasing recipient waiting list has led to the recruitment of so-called "marginal" donors. Brain death usually succeeds a period of variable intracranial pressure in which the term "coning" is often used. The classic Cushing's reflex of increased blood pressure and reduced heart rate is often discernible through monitoring and can lead to deleterious effects on multiple organ systems if not managed appropriately. There is a compensatory arterial hypertension and bradycardia (Cushing's reflex) that is followed by sympathetic stimulation with vasoconstriction, raised systemic vascular resistance and tachycardia (a triad called the catecholamine storm $)^{[83]}$. There is a redistribution of blood volume that prompts visceral ischaemia and in one study, revealed that myocardial injury occurs in $20-25 \%$ of DBD donors $^{[84]}$, with echocardiographic imaging of cardiac dysfunction evident in up to $40 \%$ of DBD donors ${ }^{[85]}$. Following this catecholamine storm phenomena, there is a profound hypotension that results from a reduction in sympathetic tone and peripheral vasodilation causing mass hypoperfusion of all organs, potentially resulting in more organ dysfunction ${ }^{[86]}$.

Cooper et al. ${ }^{[87]}$ and Novitzky et al. ${ }^{[88]}$ noted that several animal model studies carried out in South Africa in the 1980s demonstrated the catecholamine storm phenomena followed by profound hypotension occurred with reduction in cortisol, insulin, thyroid, and antidiuretic hormone levels, a switch from aerobic to anaerobic metabolism and increases in inflammation markers and cytokines. Hormonal replacement resulted in recovery of cardiac function in both experimental animals and humans, thus protecting the donor organs. Registry multivariate studies on hormonal treatment of brain-dead donors also 
revealed significant increases in organs transplanted and in 1-year survival of kidneys and hearts. Cardiac transplant centres then formed specific teams for the purpose of "optimizing" the donors with the "Papworth Cocktail"'[8] of hormones ${ }^{[00]}$. Multiple studies showed increased organ procurement and a reduction in primary graft dysfunction in transplanted hearts when triple therapy with thyroid hormone, corticosteroids and arginine vasopressin was used ${ }^{[11,92]}$.

\section{Cortisol}

It has been postulated that haemodynamic instability in DBD donors is caused by adrenal insufficiency. Nicolas-Robin et al. ${ }^{[93]}$ revealed in their cohort of brain-dead patients, adrenal insufficiency was present in almost $90 \%$. They also noted that hydrocortisone supplementation enhanced systemic haemodynamics and decreased norepinephrine dose by more than $30 \%$ in more than half of brain-dead patients with haemodynamic instability.

They also identified several pathophysiological groups based on cortisol levels and Adrenocorticotropic Hormone (ACTH) response. (1) ACTH responders with low plasma cortisol: this reflected a hypothalamicpituitary failure (secondary adrenal insufficiency) resulting from direct insult from intracranial hypertension causing ischaemia of the hypothalamus and pituitary gland, impairing the release of corticotropin-releasing hormone and ACTH as described by Novitzky et al. ${ }^{[94]}$. This group responded to tetracosactrin (synthetic ACTH) administration; (2) ACTH non-responders with normal baseline cortisol - suggesting primary adrenal failure; (3) ACTH non-responders with low baseline cortisol: this was probably caused by a hypothalamicpituitary-adrenal insufficiency; and (4) ACTH responders with normal plasma cortisol: no pathology within the hypothalamic-pituitary-adrenal axis.

Ironically, Nicolas-Robin et al. ${ }^{[93]}$ 's study demonstrated that hydrocortisone infusion was more often efficient in enhancing haemodynamic stability in ACTH nonresponders than in ACTH responders suggesting that exogenous steroids have a higher likelihood of producing a haemodynamic response when there is no endogenous response to ACTH stimulation.

It is also postulated that the effects of corticosteroid administration could be due to the re-sensitization of $\alpha$ and $\beta$-adrenoceptors pathway which are often altered by down-regulation and later by desensitization in patients with shock treated with catecholamines ${ }^{[95,96]}$. Another explanation is the "consumption" of cortisol following its initial release by the hyper-stimulated hypothalamic-pituitary-adrenal axis adrenal gland induced by brain death may be unable to replenish cortisol stores. Nicolas-Robin et al. ${ }^{[93] ' s}$ group also noted the effectiveness of hydrocortisone infusion on norepinephrine dose decrease was observed in $25 \%$ of ACTH non-responders with low baseline cortisol. The anti-inflammatory properties of hydrocortisone could also have an effect as adrenal insufficiency results from the release of several cytokines such as tumor necrosis factor $\alpha$, interleukin- 1 , interleukin- 6 , and overexpression of cell adhesion molecules such as intercellular adhesion molecule-1 and E-selectin ${ }^{[97-99]}$.

A French study involving 22 ICUs during 15 months to compare two different resuscitation strategies: systematic hydrocortisone supplementation (steroid group) or no supplementation (control group) in braindead patients who were potential organ donors was conducted. Eleven centres administered standardcare, low-dose hydrocortisone to brain-dead patients before organ procurement the remaining 11 did not administer corticosteroids ${ }^{[100]}$.

Adrenal insufficiency was noted in almost $80 \%$ of brain-dead patients. The average number of episodes ofhypotension and vascular filling volume per hour were similar in the two groups. Although more patients in the steroid group received norepinephrine before brain death, the mean dose of vasopressor administered after brain death was significantly lower than in the control group, duration of vasopressor support use was shorter than in control group and norepinephrine weaning before aortic clamping was more frequent. This decrease in number of vasopressors used following steroid administration was seen in other studies as well[101].

Dhar et al. ${ }^{[102]}$ looked at 132 consecutive brain-dead donors managed before and after changing the steroid protocol from $15 \mathrm{mg} / \mathrm{kg}$ methylprednisolone (high dose) to $300 \mathrm{mg}$ hydrocortisone (low dose) and found that the only significant differences were lower final insulin requirements and faster weaning off insulin infusions in the low dose group.

Steroid therapy was not associated with improvements in the recovery of primary graft function in these studies.

\section{Thyroxine}

Another change that occurs with brain death is the reduction of plasma-free triiodothyronine (T3) resulting in impaired aerobic metabolism. This causes a reduction of myocardial energy stores and an increased tissue lactate as a result of increased anaerobic metabolism. 
Novitzky et al. ${ }^{[103]}$ performed one of the pioneering studies in the role of T3 in transplants. One hundred and sixteen consecutive potential donors were treated, alongside 70 recipients with good immediate cardiac function in all but 3 patients, who recovered within $24 \mathrm{~h}$ of mechanical circulatory support. They also conducted 2 randomized trials in patients undergoing myocardial revascularization on cardiopulmonary bypass, and administration of post-operative T3 therapy was associated with a reduced need for inotropic support and diuretic therapy in the first study and improved cardiac output in the second study. Chen et al. ${ }^{[104]}$ 's study on rat models suggested that T3 can protect myocytes against ischemia-induced apoptosis, which may be mediated by Akt signalling.

In a study by Jeevanandam et al. ${ }^{[105]}$, donor hearts with statistically higher filling pressures, lower EF on echocardiograms, and higher inotrope requirements were resuscitated with T3 and compared to normal donors not receiving T3. All patients survived the immediate post-operative period, and at 1 week and 6 months there were no significant differences in systolic blood pressure, diastolic blood pressure, heart rate, cardiac index, central venous pressure, pulmonary capillary wedge pressure, or LVEF on echocardiography. It should also be noted that the donors also received furosemide and dopamine, both increasing renal perfusion thereby being partially responsible for the fall in pre-load and increased mean arterial pressure ${ }^{[87]}$.

Novitzky et al. ${ }^{[106]}$ then conducted a retrospective review on 63,593 donors (2000-2009) who were administered T3/T4. They noted a $12.8 \%$ increment of organs from T3/T4-treated donors compared to untreated donors $(P<0.0001)$. In study 2 , a $15.3 \%$ increase was noted $(P<0.0001)$. T3/T4 therapy was associated with procurement of significantly greater numbers of hearts, lungs, kidneys, pancreases, and intestines, but not livers. Multivariate analysis indicated a beneficial effect of T3/T4 independent of other factors $(P<0.0001)^{[105]}$. Apart from Novitzky's work however, there have been mixed reviews on the efficacy of $\mathrm{T} 3$ administration. A recent systematic review conducted by Macdonald et al. ${ }^{[107]}$ noted that all case series and retrospective audits reported a beneficial effect of thyroid hormone administration but all seven randomized controlled trials reported no benefit of thyroid hormone administration either alone or in combination with other hormonal therapies. In four placebo-controlled trials, administration of thyroid hormone had no significant effect on donor cardiac index (pooled mean difference, $0.15 \mathrm{~L} / \mathrm{min} / \mathrm{m}^{2} ; 95 \%$ confidence interval -0.18 to 0.48 ). They noted that there was a lack of consideration of confounding factors in case series and retrospective audits. However, it also notes that of the few randomized controlled trials conducted, the number of patients who were hemodynamically unstable or marginal in other ways, who would have possibly benefited from $\mathrm{T} 3$ administration was too small to exclude a benefit of thyroid hormone in this subgroup. A randomized trial by Venkateswaran et al. ${ }^{[108]}$ allocated 80 donors to four treatment groups; A control group, T3 monotherapy, Methylprednisolone monotherapy, T3 and Methylprednisolone and placebo. Pulmonary Artery Catheters were used to guide management, with vasopressin infusion commenced while weaning catecholamines at the commencement of blinded trial medication. The study found no difference in outcomes in patients from all 4 groups. They concluded that detailed donor haemodynamic measurement and management is possibly the most important criteria in increasing the yield of transplantable hearts. In animal models, administration of T3 was shown to improve haemodynamic function before and after transplantation $^{[108-110]}$.

However, this has yet to be seen in prospective randomized studies in human donors. The stance taken by most centres in the UK is to replace T3 only when there is evidence of thyroid hypofunction.

\section{Antidiuretic hormone (arginine-vasopressin)}

Antidiuretic hormone is synthesized by magnicellular neurons at the supraoptic and paraventricular nuclei, stored in neurosecretory granules in the axons that project into the posterior pituitary ${ }^{[111,112]}$. Given its anatomical location, rising intracranial pressures from the Cushing reflex as described earlier plays a part in the depletion of ADH. Yoshioka et al. ${ }^{[113]}$ first described the role of vasopressin and epinephrine vs. epinephrine alone in 16 brain-dead patients improving mean survival from 1 day to 23 days. The rise in ICP is a cause for neurogenic diabetes insipidus (DI) which is very commonly found (in some studies up to $77 \%$ of solid organ donors ${ }^{[113]}$ ), and hormone replacement with vasopressin, an effective treatment for DI, would have resolved the haemodynamic instability.

Blaine et al. ${ }^{[114]}$ noted that aggressive resuscitation with crystalloid solutions may instigate intravascular to intracellular fluid shifts thus contribute to the development of both interstitial and intracellular oedema, and ultimately result in profound hypoperfusion of end organs causing the rejection of the organs for transplantation. They conducted their study of an animal model of a brain-dead organ donor, in which polyuria, hypernatremia, and hyperosmolality developed. Low-dose (2-10 $\mathrm{microU} / \mathrm{kg} / \mathrm{min})$ vasopressin was continuously infused to maintain plasma sodium and osmolality within normal range over the course of the 
experiments. Cardiovascular function remained stable in both control and experimental vasopressin-infusion groups, with the only significant difference being a moderate rise in pulmonary artery pressure.

Rostron et al. ${ }^{[15]}$ conducted a similar study looking at the effects of arginine vasopressin in preventing neurogenic vasoplegia which exacerbates lung injury. They induced brain death in Wistar rats by inflating an intracranial balloon mimicking coning. They noted an increment in pulmonary capillary permeability, wet/dry lung weight ratios, neutrophil integrin expression and pro-inflammatory cytokines in serum (TNF- $\alpha, \mathrm{IL}-1 \beta$, CINC-1 and CINC-3), bronchoalveolar lavage (TNF- $\alpha$, IL-1 $\beta$,) and lung tissue (IL-1 $\beta$ and CINC-1) in braindead animals compared to controls. These effects were corrected by administration of arginine vasopressin (AVP) and norepinephrine to correct the neurogenic hypotension.

Another study conducted by Chen et al. ${ }^{[116]}$ investigated vasopressin deficiency and hypersensitivity as a potential contributing factor to hypotension in organ donors. In their cohort of 50 organ donors, 10 patients were treated with a continuous infusion of vasopressin (0.04 to $0.1 \mathrm{U} / \mathrm{min}$ ). Mean arterial pressure (MAP), catecholamine requirements, serum vasopressin, and serum osmolality were obtained before and after vasopressin administration. An increment of MAP allowed complete discontinuation of catecholamine pressors in $40 \%$ of patients and a decrement in pressor dose in another $40 \%$. Plasma vasopressin levels $(2.9 \pm 0.8 \mathrm{pg} / \mathrm{mL})$ were notably low for the degree of hypotension. It is likely that haemodynamically unstable organ donors may not only display diabetes insipidus but also have a defect in baroreflex-mediated secretion of vasopressin, for which supplementation would permit catecholamine sparing. The catecholamine sparing effects of vasopressin were also noted by Pennefather et al. ${ }^{[117]}$ in which 24 DBD donors were randomised to receive either saline or low dose AVP. The AVP group had a decreased plasma hyperosmolality $(P<0.05)$, improved blood pressure $(P<0.01)$, and reduced inotrope use $(P<0.01)$, while maintaining cardiac output. Myocardial ATP levels were higher in the AVP than the control group (NS). Kinoshita et al. ${ }^{[18]}$ studied the effects of epinephrine and arginine vasopressin in 10 brain dead patients. Patients maintained haemodynamic stability for more than a week with an initial rise in ST wave changes that was reversible. This was confirmed by a normal level of CK-MB and normal or slightly swollen mitochondria on cardiac biopsy specimens, highlighting the role of both arginine vasopressin and epinephrine in maintaining haemodynamic stability post brain death. Papadopoulos et al. ${ }^{[119]}$ found that vasopressin administration reduced the dose of requirements of catecholamines and contributed to prevention of the post-cardiotomy vasoplegic shock in the patient with low ejection fraction (30-40\%) on ACE inhibitors in a double blind randomized controlled trial whereby the group A who were infused with low dose vasopressin and the group $B$ who were infused with normal saline intraoperatively and for the 4 post-operative hours. This further illustrated the benefits of vasopressin out with the correction of neurogenic diabetes insipidus.

\section{Glucose-Insulin-Potassium}

Calva et al. ${ }^{[120]}$ first conducted experiments on canines by inducing myocardial infarctions via coronary artery ligation noting the extent of damage to the mitochondria with and without glucose-insulin-potassium regimes in the 60s. Opie et al. ${ }^{[121]}$ conducted similar studies with baboons and noted similar findings, a reduction in mitochondrial damage and decreased infarction and reduced ST segment depression on EKG. Multiple studies have since been done to study the effect of glucose-potassium-insulin (GKI) on myocyte function. Human studies were first pioneered by Sodi-Pallares et al. ${ }^{[122]}$ in which 10 patients with acute myocardial infarction and 20 patients with chronic coronary insufficiency, with 3 patients showing improvements but 2 patients worsening and a general improvement in the chronic patients. A meta-analysis however revealed no reduction in mortality in patients receiving GKI in randomised studies ${ }^{[123]}$. They concluded that while it may have had a potential benefit in the prerevascularisation and thrombolysis era, its benefits are not clearly evident now. Sun et al. ${ }^{[124]}$ investigated the role of GKI for prevention of oxygen free radical injury during reperfusion of ischaemic stored hearts. Comparing known free radical scavengers (superoxide dismustase and catalase) alone and combination with GKI in rat models, they noted that there was no added benefit of GKI infusion in reduction reperfusion injury once reperfusion was commenced, but noted an improvement in the superoxide dismustase and catalase infusion group. A significant improvement however was noted when GKI and the free radical scavengers were combined showing improvement in left ventricular end-diastolic pressure, myocardial blood flow. They concluded that free radical scavengers in the presence of glucose-insulin-potassium significantly improve functional recovery in the setting of heart transplantation.Myocardial dysfunction that occurs post brain death is a phenomenon that is ubiquitously reported but not fully understood. It is thought to be related to direct myocardial injury from sympathetic activation $^{[125]}$, potential reduction in oxidative metabolism from the reduction in T3, variability 
of loading conditions, endothelial dysfunction and impairment of coronary blood flow ${ }^{[126]}$.

Nicolas-Robin et al. ${ }^{[127]}$ looked at GKI infusion in comparison to dobutamine for in DBD donors. They found that a GKI infusion significantly improved the systolic dysfunction comparably to dobutamine without its inherent side effects of peripheral vasodilation, potential arrhythmogenesis, and tachycardia. This was thought to be possibly due to an adaptive hibernating state of the myocardium to reduce myocardial oxygen demand, thereby allowing a longer period of ischaemia without necrosis ${ }^{[128]}$. Hence the rationale behind GKI infusion is by replenishing the energy supply of the failing heart, by switching metabolism from oxidation of fatty acids (glycogenolysis) to oxidation of glucose (glycolysis) and lactate ${ }^{[129]}$. This allows restoration of calcium homeostasis and replenishment of glycogen stores by increasing the rate of ATP ${ }^{[130]}$. Although GKI was not shown to improve mortality in acute myocardial infarction as mentioned above, there may be a role for it in the ischaemic myocardium.

Cottin et al. ${ }^{[131]}$ demonstrated that their cohort of patients with heart failure (Ejection Fraction $<45 \%$ ), GKI infusion reduced Wall Motion Score Index and increased ejection fraction significantly in their small study. Similar findings were noted in several other studies, including a reduction in BNP concentrations ${ }^{[132-135]}$.

\section{ISCHAEMIC CONDITIONING}

Reperfusion injury is postulated to be a key contributing factor for primary graft dysfunction, thus the role of ischaemic conditioning whilst still in its trialling phase may be of benefit. The lack of evidence of benefit in large scale studies such as RIPheart ${ }^{[136]}$ and ERICCA ${ }^{[137]}$ clarified that this intervention does not confer any benefits to patients undergoing CABG.

Animal models have shown potential benefits and cardioprotective mechanisms, but while biochemical improvements were noted by the ERICCA trial (reduced troponin levels), its relevance remains to be seen. Remote ischaemic preconditioning (RIC) and remote ischaemic post conditioning (PostC) work on the premise that brief episodes of ischemia and reperfusion to the remote organ protect the heart by a paracrine or neural-reflex mechanism while avoiding additional stress on the heart itself ${ }^{[138]}$.

Thielmann et al. ${ }^{[139]}$ conducted the first single centre randomised, double blind controlled trial of RIC in 329 patients from 2008-2012. They found a significantly lower troponin level (cTnl) in the RIC group compared to the control group and the all-cause mortality was assessed over 1.54 (SD 1.22) years and was lower with remote ischaemic preconditioning than without (ratio $0.27,95 \% \mathrm{Cl} 0.08-0.98, P=0.046)^{[137]}$. Hong et al..$^{[140]}$ however failed to demonstrate any difference between the groups but it should be noted that he included RIC with PostC in 1280 patients and had a much broader composite of outcomes. Hong's group also failed to record any biomarkers, limiting the end-points to solely clinical outcomes.

Sachdeva et al. ${ }^{[141]}$ noted no subsequent benefit in both remote preconditioning and postconditioning alone or in combination and observed that they failed to attenuate infarct size in an anesthetized rat model with myocardial infarction. There was also no recovery of LV dysfunction induced by ischemia-reperfusion injury.

However, the recently concluded randomized LipsiaConditioning ${ }^{[142]}$ trial studied the effects of RIC and PostC revealed conflicting evidence to this. Using cardiac magnetic resonance to quantify myocardial injury, they showed that combined intra-hospital RIC and PostC significantly increases myocardial salvage when compared with conventional $\mathrm{PCl}$, whereas PostC alone failed to demonstrate a cardioprotective effect in STEMI patients undergoing primary $\mathrm{PCl}$.

Another article by Pichot et al. ${ }^{[143]}$ however revealed PostC had a significant effect in reducing myocardial injury independently of traditional cardiovascular risk factors in patients with STEMI.

Ischaemic conditioning has garnered a lot of interest in recent times with almost 500 articles published every year, and 53 clinical trials (phase I to IV) available on PubMed. Of these 37 clinical trials are specific to cardiac surgery alone ${ }^{[144]}$. A lot of the RIC data in other studies have focused on biomarkers of cardiac injury and not outcomes, which were the endpoints for both RIPheart and ERICCA. To date, no adequately powered and randomised trial has looked at the effect of RIC and PostC in transplantation, and given the recent findings of large trials in CABGs, an adequately powered trial in transplant cannot be justified. The negative results have generated more discussion and questions with better discourse into methodology. For example, in Kottenberg et al. ${ }^{[145]}$ 's study, propofol was a potential confounding factor. Propofol interferes with the activation of the signal transducer and activator of transcription 5 (STAT5) pathway. A recent study by Kleinbongard et al. ${ }^{[146]}$ looking at confounders that may affect the efficacy of RIC found that patients with an aortic cross-clamp time of $<56$ min had no protection by RIC whereas there was solid protection 
by RIC at cross-clamp times of 57-75 min (ratio of RIC/ control $=0.757 ; P=0.0348$ ) and of $\geq 76 \mathrm{~min}$ (ratio of $\mathrm{RIC} /$ control $=0.735 ; P=0.0277)^{[146]}$. RIC theoretically confers protection against ischaemia but not trauma during surgery (cannulation/handling); thus making it plausible that in longer cross-clamp times, the protection conferred by RIC becomes more overt due to the effect of ischaemic/reperfusion injury. Another recent study what studied the effect of preconditioning with cyclosporine-A (which prevents MPTP opening at the onset of reperfusion, thereby also reducing the incidence of ischaemic-reperfusion injury ${ }^{[147]}$ in patients undergoing elective CABG revealed similar findings, with the cardioprotective benefits noted at longer cross-clamp times (85-120 $\mathrm{min}$ ) but not in the shorter (50-85 min) group ${ }^{[148]}$.

lyer et al. ${ }^{[149]}$ utilised PostC in DCD hearts using a porcine asphyxia model and subjected them to warm ischaemic times of 20-40 min prior to flushing with Celsior solution. The solution was supplemented with erythropoietin ${ }^{[150]}$, glyceryl trinitrate ${ }^{[151,152]}$ and zoniporide $(\mathrm{Cs})^{[153]}$, a combination that activates ischaemic postconditioning pathways.

Hearts were assessed for functional, biochemical and metabolic recovery on an ex-vivo working heart apparatus. Hearts with postconditioning pathways activated demonstrated complete recovery up to 20 -min of warm ischaemia time after which a rapid decline ensued.

\section{CONCLUSION}

There have been multiple recent advances in recent times with specific interest in myocardial protection. The search for biomarkers however continue to persist and may provide a gauge to quantify myocardial damage. Continuous normothermic organ perfusion remains an interesting prospect that allows transport and working assessment of the heart prior to transplantation. This has revolutionised DCD transplantation thus added more organs to the potential donor pool. Short term outcomes of DCD hearts have been good, however longterm outcomes need to be studied to allow widespread use. The role of ischaemic pre- and post-conditioning remain uncertain in the field of cardiac transplantation. A summation of myocardial protection strategies may be the way forward.

\section{DECLARATIONS}

\section{Authors' contributions}

Writing: S.S.A. Singh

Conceptualisation: N. Al-Attar
Table design: S. Das De

Reviewing, editing, supervision: C. Spadaccio, C. Berry, N. Al-Attar

\section{Financial support and sponsorship None.}

\section{Conflicts of interest}

There are no conflicts of interest.

\section{Patient consent \\ Not applicable.}

\section{Ethics approval \\ Not applicable.}

\section{REFERENCES}

1 Ravishankar V. March of cardiac surgery through the decades. Med J Armed Forces India 2014;70:3-4.

2. Konstantinov IE. At the cutting edge of the impossible: a tribute to Vladimir P. Demikhov. Tex Heart Inst J 2009;36:453-8.

3. Lower RR, Stofer RC, Hurley EJ, Dong E Jr, Cohn RB, Shumway NE. Successful homotransplantation of the canine heart after anoxic preservation for seven hours. Am J Surg 1962;104:302-6.

4. Dong E Jr, Hurley EJ, Lower RR, Shumway NE. Performance of the heart two years after autotransplantation. Surgery 1964;56:270-4.

5. Shumway NE, Lower RR. Special problems in transplantation of the heart. Ann N Y Acad Sci 1964;120:773-7.

6. Barnard $\mathrm{CN}$. The operation. A human cardiac transplant: an interim report of a successful operation performed at Groote Schuur Hospital, Cape Town. S Afr Med J 1967;41:1271-4.

7. Lansman SL, Ergin MA, Griepp RB. The history of heart and heartlung transplantation. Cardiovasc Clin 1990;20:3-19.

8. Stehlik J, Edwards LB, Kucheryavaya AY, Aurora P, Christie JD, Kirk R, Dobbels F, Rahmel AO, Hertz MI. The registry of the international society for heart and lung transplantation: twenty-seventh official adult heart transplant report--2010. J Heart Lung Transplant 2010;29:1089103.

9. Lietz K, Miller LW. Improved survival of patients with end-stage heart failure listed for heart transplantation: analysis of organ procurement and transplantation network/U.S. United Network of Organ Sharing data, 1990 to 2005. J Am Coll Cardiol 2007;50:1282-90.

10. Abuanzeh R, Hashmi F, Dimarakis I, Khasati N, Machaal A, Yonan $\mathrm{N}$, Venkateswaran RV. Early donor management increases the retrieval rate of hearts for transplantation in marginal donors. Eur $J$ Cardiothorac Surg 2015;47:72-7; discussion 77.

11. Ringer S. A further contribution regarding the influence of the different constituents of the blood on the contraction of the heart. $J$ Physiol 1883;4:29-42.

12. Tyers GF, Todd GJ, Niebauer IM, Manley NJ, Waldhausen JA.. The mechanism of myocardial damage following potassium citrate (Melrose) cardioplegia. Surgery 1975;78:45-53.

13. Maathuis MH, Leuvenink HG, Ploeg RJ. Perspectives in organ preservation. Transplantation 2007;83:1289-98.

14. tHart NA, Leuvenink HGD, Ploeg RJ. New solutions in organ preservation. Available from: http://www.sciencedirect.com/science/ article/pii/S0955470X02800027. [Last accessed on 20 Oct 2017]

15. Shumway NE, Lower RR. Topical cardiac hypothermia for extended periods of anoxic arrest. Surg Forum 1960;10:563-6. 
16. Blaisdell FW, Cooley DA. The mechanism of paraplegia after temporary thoracic aortic occlusion and its relationship to spinal fluid pressure. Surgery 1962;51:351-5.

17. Kay EB, Head LR, Nogueira C. Direct coronary artery perfusion for aortic valve surgery; report of technique. $J$ Am Med Assoc 1958;168:1767-8.

18. Senning A. Ventricular fibrillation during hypothermia, used as a method to facilitate intracardiac operations. Acta Chir Scand 1955;109:303-9.

19. Bretschneider HJ, Hübner G, Knoll D, Lohr B, Nordbeck H, Spieckermann PG. Myocardial resistance and tolerance to ischemia: physiological and biochemical basis. J Cardiovasc Surg (Torino) 1975;16:241-60.

20. Hearse DJ, Stewart DA, Braimbridge MV. Cellular protection during myocardial ischemia: the development and characterization of a procedure for the induction of reversible ischaemic arrest. Circulation 1976;54:193-202.

21. Buckberg GD. Recent progress in myocardial protection during cardiac operations. Cardiovasc Clin 1987;17:291-319.

22. Hearse DJ, Humphrey SM, Nayler WG, Slade A, Border D. Ultrastructural damage associated with reoxygenation of the anoxic myocardium. J Mol Cell Cardiol 1975;7:315-24.

23. Chambers DJ, Fallouh HB. Cardioplegia and cardiac surgery: pharmacological arrest and cardioprotection during global ischemia and reperfusion. Pharmacol Ther 2010;127:41-52.

24. Reichenspurner H, Russ C, Uberfuhr P, Nollert G, Schlüter A, Reichart B, Klövekorn WP, Schüler S, Hetzer R, Brett W. Myocardial preservation using HTK solution for heart transplantation. A multicenter study. Eur J Cardiothorac Surg 1993;7:414-9.

25. Sung SY, Lin CY, Song JY, Tsai YT, Kao CH, Lee CY, Lin YC, Hsu PS, Tsai CS. Myocardial protection in donor heart preservation: a comparison between Bretschneider's histidine-tryptophanketoglutarate solution and cold blood cardioplegia. Transplant Proc 2014;46:1077-81.

26. Minami K, Omoto T, Böthig D, Tenderich G, Wlost S, Schütt U, Körfer R. Creatine kinase and troponin after myocardial preservation using HTK solution (Custoidol) for clinical heart transplantation. $J$ Heart Lung Transplant 2003;22:192-4.

27. Larsen M, Webb G, Kennington S, Kelleher N, Sheppard J, Kuo J, Unsworth-White J. Mannitol in cardioplegia as an oxygen free radical scavenger measured by malondialdehyde. Perfusion 2002;17:51-5.

28. Cordell AR. Milestones in the development of cardioplegia. Ann Thorac Surg 1995;60:793-6.

29. Chambers DJ, Sakai A, Braimbridge MV, Kosker S, Manzanera G, Kind PR, Jupp RA, Smith LD, Slavin B.Clinical validation of St. Thomas' hospital cardioplegic solution No. 2 (Plegisol). Eur J Cardiothorac Surg 1989;3:346-52.

30. Luciani GB, Faggian G, Montalbano G, Casali G, Forni A, Chiominto B, Mazzucco A. Blood versus crystalloid cardioplegia for myocardial protection of donor hearts during transplantation: a prospective, randomized clinical trial. J Thorac Cardiovasc Surg 1999;118:787-95.

31. Luciani GB, Forni A, Rigatelli G, Chiominto B, Cardaioli P, Mazzucco A, Faggian G. Myocardial protection in heart transplantation using blood cardioplegia: 12-year outcome of a prospective randomized trial. J Heart Lung Transplant 2011;30:29-36.

32. Collins GM, Hartley LC, Clunie GJ. Kidney preservation for transportation. Experimental analysis of optimal perfusate composition. Br J Surg 1972;59:187-9.

33. Andrews PM, Bates SB. Improving Euro-Collins flushing solution's ability to protect kidneys from normothermic ischemia. Miner Electrolyte Metab 1985;11:309-13.

34. Hendry PJ, Labow RS, Keon WJ. A comparison of intracellular solutions for donor heart preservation. J Thorac Cardiovasc Surg 1993;105:667-73.
35. James H. Southard MDa, Folkert O. Belzer MD. ORGAN PRESERVATION. Ann Rev Med 1995;46:235-47.

36. Ploeg RJ, Goossens D, McAnulty JF, Southard JH, Belzer FO. Successful 72-hour cold storage of dog kidneys with UW solution. Transplantation 1988;46:191-6.

37. Todo S, Nery J, Yanaga K, Podesta L, Gordon RD, Starzl TE. Extended preservation of human liver grafts with UW solution. JAMA 1989;261:711-4.

38. Jamieson NV, Sundberg R, Lindell S, Claesson K, Moen J, Vreugdenhil PK, Wight DG, Southard JH, Belzer FO. Preservation of the canine liver for 24-48 hours using simple cold storage with UW solution. Transplantation 1988;46:517-22.

39. Kozlova I, Khalid Y, Roomans GM. Preservation of mouse liver tissue during cold storage in experimental solutions assessed by $\mathrm{x}$-ray microanalysis. Liver Transpl 2003;9:268-78.

40. Vreugdenhil PK, Belzer FO, Southard JH. Effect of cold storage on tissue and cellular glutathione. Cryobiology 1991;28:143-9.

41. Biguzas M, Jablonski P, Howden BO, Thomas AC, Walls K, Scott DF, Marshall VC. Evaluation of UW solution in rat kidney preservation. II. The effect of pharmacological additives. Transplantation 1990;49:1051-5.

42. Kur F, Beiras-Fernandez A, Meiser B, Uberfuhr P, Reichart B. Clinical heart transplantation with extended preservation time $(>5$ hours): experience with University of Wisconsin solution. Transplant Proc 2009;41:2247-9.

43. Jeevanandam V, Barr ML, Auteri JS, Sanchez JA, Fong J, Schenkel FA, Marboe CC, Michler RE, Smith CR, Rose EA.University of Wisconsin solution versus crystalloid cardioplegia for human donor heart preservation. A randomized blinded prospective clinical trial. $J$ Thorac Cardiovasc Surg 1992;103:194-8; discussion 198-9.

44. Mankad P, Slavik Z, Yacoub M. Endothelial dysfunction caused by University of Wisconsin preservation solution in the rat heart. The importance of temperature. J Thorac Cardiovasc Surg 1992;104:1618-24.

45. Saitoh Y, Hashimoto M, Ku K, Kin S, Nosaka S, Masumura S, Nakayama $\mathrm{K}$. Heart preservation in HTK solution: role of coronary vasculature in recovery of cardiac function. Ann Thorac Surg 2000;69:107-12.

46. De Santo LS, Amarelli C, Romano G, Della Corte A, Maiello C, Giannolo B, Marra C, De Feo M, Scardone M, Cotrufo M. Highrisk heart grafts: effective preservation with Celsior solution. Heart Vessels 2006;21:89-94.

47. Careaga G, Salazar D, Téllez S, Sánchez O, Borrayo G, Argüero R. Clinical impact of histidine-ketoglutarate-tryptophan (HTK) cardioplegic solution on the perioperative period in open heart surgery patients. Arch Med Res 2001;32:296-9.

48. Lee KC, Chang CY, Chuang YC, Sue SH, Yang HS, Weng CF, Lee YT, Huang WS, Chen IC, Wei J.Combined St. Thomas and histidinetryptophan-ketoglutarat solutions for myocardial preservation in heart transplantation patients. Transplant Proc 2012;44:886-9.

49. Careaga G, Salazar D, Téllez S, Sánchez O, Borrayo G, Argüero R.Clinical impact of histidine-ketoglutarate-tryptophan (HTK) cardioplegic solution on the perioperative period in open heart surgery patients. Arch Med Res 2001;32:296-9.

50. Vega JD, Ochsner JL, Jeevanandam V, McGiffin DC, McCurry KR, Mentzer RM Jr, Stringham JC, Pierson RN 3rd, Frazier OH, Menkis AH, Staples ED, Modry DL, Emery RW, Piccione W Jr, Carrier M, Hendry PJ, Aziz S, Furukawa S, Pham SM. A multicenter, randomized, controlled trial of Celsior for flush and hypothermic storage of cardiac allografts. Ann Thorac Surg 2001;71:1442-7.

51. Wieselthaler GM, Chevtchik O, Konetschny R, Moidl R, Mallinger R, Mares P, Griessmacher A, Grimm M, Wolner E, Laufer G. Improved graft function using a new myocardial preservation solution: Celsior. Preliminary data from a randomized prospective study. Transplant Proc 1999;31:2067-8.

52. Cannata A, Botta L, Colombo T, Russo CF, Taglieri C, Bruschi G, 
Merlanti B, Frigerio M, Martinelli L. Does the cardioplegic solution have an effect on early outcomes following heart transplantation? Eur J Cardiothorac Surg 2012;41:e48-52; discussion e52-3.

53. George TJ, Arnaoutakis GJ, Beaty CA, Shah AS, Conte JV, Halushka MK. A novel method of measuring cardiac preservation injury demonstrates University of Wisconsin solution is associated with less ischaemic necrosis than Celsior in early cardiac allograft biopsy specimens. J Heart Lung Transplant 2012;31:410-8.

54. George TJ, Arnaoutakis GJ, Baumgartner WA, Shah AS, Conte JV. Organ storage with University of Wisconsin solution is associated with improved outcomes after orthotopic heart transplantation. $J$ Heart Lung Transplant 2011;30:1033-43.

55. Kofler S, Bigdeli AK, Kaczmarek I, Kellerer D, Müller T, Schmoeckel M, Steinbeck G, Uberfuhr P, Reichart B, Meiser B. Long-term outcomes after 1000 heart transplantations in six different eras of innovation in a single center. Transpl Int 2009;22:1140-50.

56. Garlicki M, Kołcz J, Rudziński P, Kapelak B, Sadowski J, Wójcik S, Pietrzyk E, Frasik W, Drukała J, Dziatkowiak A. Myocardial protection for transplantation. Transplant Proc 1999;31:2079-83.

57. Lee S, Huang CS, Kawamura T, Shigemura N, Billiar TR, Nakao A, Toyoda Y. Histidine-tryptophan-ketoglutarate or celsior: which is more suitable for cold preservation for cardiac grafts from older donors? Ann Thorac Surg 2011;91:755-63.

58. Ackemann J, Gross W, Mory M, Schaefer M, Gebhard MM. Celsior versus custodiol: early postischemic recovery after cardioplegia and ischemia at 5 degrees C. Ann Thorac Surg 2002;74:522-9.

59. Lurati Buse GA, Koller MT, Grapow M, Bolliger D, Seeberger M, Filipovic M. The prognostic value of troponin release after adult cardiac surgery - a meta-analysis. Eur J Cardiothorac Surg 2010;37:399-406.

60. De Santo LS, Torella M, Romano G, Maiello C, Buonocore M, Bancone C, Della Corte A, Galdieri N, Nappi G, Amarelli C. Perioperative myocardial injury after adult heart transplant: determinants and prognostic value. PLoS One 2015;10:e120813.

61. Gross GJ, Kersten JR, Warltier DC. Mechanisms of postischemic contractile dysfunction. Ann Thorac Surg 1999;68:1898-904.

62. Dengler TJ, Gleissner CA, Klingenberg R, Sack FU, Schnabel PA, Katus HA. Biomarkers after heart transplantation: nongenomic. Heart Fail Clin 2007;3:69-81.

63. Masuda M, Morita S, Tomita H, Kurisu K, Nishida T, Tominaga R, Yasui H. Off-pump CABG attenuates myocardial enzyme leakage but not postoperative brain natriuretic peptide secretion. Ann Thorac Cardiovasc Surg 2002;8:139-44.

64. Hajjar L, Galas F, Grande S, Campos M, Silva R, Marques A, Leao W, Auler Jr J. Plasma brain natriuretic peptide and cardiac troponin I concentrations after adult cardiac surgery: association with cardiovascular death, postoperative cardiac, renal and pulmonary dysfunction. Available from: https://ccforum.biomedcentral.com/ track/pdf/10.1186/cc6665. [Last accessed on 20 Oct 2017]

65. McIlroy DR, Wallace S, Roubos N. Brain natriuretic peptide (BNP) as a biomarker of myocardial ischemia-reperfusion injury in cardiac transplantation. J Cardiothorac Vasc Anesth 2010;24:939-45.

66. Cavarretta E, Frati G. MicroRNAs in coronary heart disease: ready to enter the clinical arena? Biomed Res Int 2016;2016:2150763.

67. Wang E, Nie Y, Zhao Q, Wang W, Huang J, Liao Z, Zhang H, Hu $\mathrm{S}$, Zheng Z. Circulating miRNAs reflect early myocardial injury and recovery after heart transplantation. J Cardiothorac Surg 2013;8:165.

68. Russo MJ, Chen JM, Sorabella RA, Martens TP, Garrido M, Davies RR, George I, Cheema FH, Mosca RS, Mital S, Ascheim DD, Argenziano M, Stewart AS, Oz MC, Naka Y. The effect of ischaemic time on survival after heart transplantation varies by donor age: an analysis of the United Network for organ sharing database. $J$ Thorac Cardiovasc Surg 2007;133:554-9.

69. Goldsmith KA, Demiris N, Gooi JH, Sharples LD, Jenkins DP, Dhital KK, Tsui SS. Life-years gained by reducing donor heart ischaemic times. Transplantation 2009;87:243-8.

70. Hassanein WH, Zellos L, Tyrrell TA, Healey NA, Crittenden MD, Birjiniuk V, Khuri SF. Continuous perfusion of donor hearts in the beating state extends preservation time and improves recovery of function. J Thorac Cardiovasc Surg 1998;116:821-30.

71. Messer S, Ardehali A, Tsui S. Normothermic donor heart perfusion: current clinical experience and the future. Transpl Int 2015;28:634-42.

72. Tenderich G, El-Banayosy A, Rosengard B, Tsui S, Wallwork J, Hetzer R, Koerfer R, Hassanein W. 10: Prospective multi-center European trial to evaluate the safety and performance of the Organ Care System for heart transplants (PROTECT). Available from: http:// www.jhltonline.org/article/S1053-2498(06)00824-2/fulltext. [Last accessed on 20 Oct 2017]

73. McCurry K, Jeevanandam V, Mihaljevic T, Couper G, Elanwar M, Saleh H, Ardehali A. 294: Prospective Multi-center safety and effectiveness evaluation of the Organ Care System device for cardiac use (PROCEED). Available from: http://www.jhltonline.org/article/ S1053-2498(07)01142-4/abstract. [Last accessed on 20 Oct 2017]

74. Hamed A, Tsui S, Huber J, Lin R, Poggio EC, Ardehali A. 19: Serum lactate is a highly sensitive and specific predictor of post cardiac transplant outcomes using the Organ Care System. J Heart Lung Transplant 2009;28:S71.

75. Ardehali A, Esmailian F, Deng M, Soltesz E, Hsich E, Naka Y, Mancini D, Camacho M, Zucker M, Leprince P, Padera R, Kobashigawa J; PROCEED II trial investigators. Ex-vivo perfusion of donor hearts for human heart transplantation (PROCEED II): a prospective, open-label, multicentre, randomised non-inferiority trial. Lancet 2015;385:2577-84.

76. Daemen JW, Kootstra G, Wijnen RM, Yin M, Heineman E. Nonheartbeating donors: the Maastricht experience. Clin Transpl 1994:303-16.

77. Iyer A, Gao L, Doyle A, Rao P, Cropper JR, Soto C, Dinale A, Kumarasinghe G, Jabbour A, Hicks M, Jansz PC, Feneley MP, Harvey RP, Graham RM, Dhital KK, MacDonald PS. Normothermic ex vivo perfusion provides superior organ preservation and enables viability assessment of hearts from DCD donors. Am J Transplant 2015;15:371-80

78. Dhital KK, Iyer A, Connellan M, Chew HC, Gao L, Doyle A, Hicks M, Kumarasinghe G, Soto C, Dinale A, Cartwright B, Nair P, Granger E, Jansz P, Jabbour A, Kotlyar E, Keogh A, Hayward C, Graham R, Spratt P, Macdonald P. Adult heart transplantation with distant procurement and ex-vivo preservation of donor hearts after circulatory death: a case series. Lancet 2015;385:2585-91.

79. Boucek MM, Mashburn C, Dunn SM, Frizell R, Edwards L, Pietra B, Campbell D; Denver Children's Pediatric Heart Transplant Team. Pediatric heart transplantation after declaration of cardiocirculatory death. N Engl J Med 2008;359:709-14.

80. Walsh F. Europe's first non-beating heart transplant. Available from: http://www.bbc.com/news/health-32056350. [Last accessed on 20 Oct 2017]

81. Truog RD, Miller FG, Halpern SD. The dead-donor rule and the future of organ donation. $N$ Engl J Med 2013;369:1287-9.

82. Ullah S, Zabala L, Watkins B, Schmitz ML. Cardiac organ donor management. Perfusion 2006;21:93-8.

83. Cuisinier A, Maufrais C, Payen JF, Nottin S, Walther G, Bouzat P. Myocardial function at the early phase of traumatic brain injury: a prospective controlled study. Scand J Trauma Resusc Emerg Med 2016;24:129.

84. Novitzky D, Rhodin J, Cooper DK, Ye Y, Min KW, DeBault L. Ultrastructure changes associated with brain death in the human donor heart. Transpl Int 1997;10:24-32.

85. Kilic A, Emani S, Sai-Sudhakar CB, Higgins RS, Whitson BA. Donor selection in heart transplantation. J Thorac Dis 2014;6:1097-104.

86. Lee H, Cho YH, Sung K, Yang JH, Chung CR, Jeon K, Suh GY. The use of extracorporeal circulation in suspected brain dead organ donors 
with cardiopulmonary collapse. J Korean Med Sci 2015;30:1911-4.

87. Cooper LB, Milano CA, Williams M, Swafford W, Croezen D, Van Bakel AB, Rogers JG, Patel CB. Thyroid hormone use during cardiac transplant organ procurement. Clin Transplant 2016;30:1578-83.

88. Novitzky D, Cooper DK, Rosendale JD, Kauffman HM. Hormonal therapy of the brain-dead organ donor: experimental and clinical studies. Transplantation 2006;82:1396-401.

89. Novitzky D, Cooper DK, Wicomb W. Hormonal therapy to the braindead potential organ donor: the misnomer of the "Papworth cocktail". Transplantation 2008;86:1479.

90. Wheeldon DR, Potter CD, Oduro A, Wallwork J, Large SR. Transforming the "unacceptable" donor: outcomes from the adoption of a standardized donor management technique. J Heart Lung Transplant 1995;14:734-42.

91. Wojda TR, Stawicki SP, Yandle KP, Bleil M, Axelband J, WildeOnia R, Thomas PG, Cipolla J, Hoff WS, Shultz J. Keys to successful organ procurement: an experience-based review of clinical practices at a high-performing health-care organization. Int J Crit Illn Inj Sci 2017;7:91-100.

92. Hahnenkamp K, Böhler K, Wolters H, Wiebe K, Schneider D, Schmidt HH. Organ-protective intensive care in organ donors. Dtsch Arztebl Int 2016;113:552-8.

93. Nicolas-Robin A, Barouk JD, Amour J, Coriat P, Riou B, Langeron O. Hydrocortisone supplementation enhances hemodynamic stability in brain-dead patients. Anesthesiology 2010;112:1204-10.

94. Novitzky D, Cooper DK, Muchmore JS, Zuhdi N. Pituitary function in brain-dead patients. Transplantation 1989;48:1078-9.

95. Barnes PJ. Beta-adrenergic receptors and their regulation. Am J Respir Crit Care Med 1995;152:838-60.

96. Clemente G, Tuttolomondo A, Colomba D, Pecoraro R, Renda C, Della Corte V, Maida C, Simonetta I, Pinto A. When sepsis affects the heart: a case report and literature review. World J Clin Cases 2015;3:743-50.

97. McLean KM, Duffy JY, Pandalai PK, Lyons JM, Bulcao CF, Wagner CJ, Akhter SA, Pearl JM. Glucocorticoids alter the balance between pro- and anti-inflammatory mediators in the myocardium in a porcine model of brain death. $J$ Heart Lung Transplant 2007;26:78-84.

98. Guglin M. How to increase the utilization of donor hearts? Heart Fail Rev 2015;20:95-105.

99. Pandit RA, Zirpe KG, Gurav SK, Kulkarni AP, Karnath S, Govil D, Abhram B, Mehta Y, Gupta A, Hegde A, Patil V, Bhatacharya P, Dixit S, Samavedan S, Todi S. Management of potential organ donor: Indian society of critical care medicine: position statement. Indian $J$ Crit Care Med 2017;21:303-16.

100. Pinsard M, Ragot S, Mertes PM, Bleichner JP, Zitouni S, Cook F, Pierrot M, Dube L, Menguy E, Lefèvre LM, Escaravage L, Dequin PF, Vignon P, Pichon N. Interest of low-dose hydrocortisone therapy during brain-dead organ donor resuscitation: the CORTICOME study. Crit Care 2014;18:R158.

101. Dimopoulou I, Tsagarakis S, Anthi A, Milou E, Ilias I, Stavrakaki K, Charalambidis C, Tzanela M, Orfanos S, Mandragos K, Thalassinos $\mathrm{N}$, Roussos C. High prevalence of decreased cortisol reserve in braindead potential organ donors. Crit Care Med 2003;31:1113-7.

102. Dhar R, Cotton C, Coleman J, Brockmeier D, Kappel D, Marklin G, Wright R. Comparison of high- and low-dose corticosteroid regimens for organ donor management. J Crit Care 2013;28:111.e1-7.

103. Novitzky D, Cooper DK, Chaffin JS, Greer AE, DeBault LE, Zuhdi N. Improved cardiac allograft function following triiodothyronine therapy to both donor and recipient. Transplantation 1990;49:311-6.

104. Chen YF, Kobayashi S, Chen J, Redetzke RA, Said S, Liang Q, Gerdes AM. Short term triiodo-L-thyronine treatment inhibits cardiac myocyte apoptosis in border area after myocardial infarction in rats. $J$ Mol Cell Cardiol 2008;44:180-7.

105. Jeevanandam V, Todd B, Regillo T, Hellman S, Eldridge C, McClurken J. Reversal of donor myocardial dysfunction by triiodothyronine replacement therapy. J Heart Lung Transplant 1994;13:681-7; discussion 685-7.

106. Novitzky D, Mi Z, Sun Q, Collins JF, Cooper DK. Thyroid hormone therapy in the management of 63,593 brain-dead organ donors: a retrospective analysis. Transplantation 2014;98:1119-27.

107. Macdonald PS, Aneman A, Bhonagiri D, Jones D, O’Callaghan G, Silvester W, Watson A, Dobb G. A systematic review and metaanalysis of clinical trials of thyroid hormone administration to brain dead potential organ donors. Crit Care Med 2012;40:1635-44.

108. Venkateswaran RV, Steeds RP, Quinn DW, Nightingale P, Wilson IC, Mascaro JG, Thompson RD, Townend JN, Bonser RS. The haemodynamic effects of adjunctive hormone therapy in potential heart donors: a prospective randomized double-blind factorially designed controlled trial. Eur Heart J 2009;30:1771-80.

109. Novitzky D, Wicomb WN, Cooper DK, Tjaalgard MA. Improved cardiac function following hormonal therapy in brain dead pigs: relevance to organ donation. Cryobiology 1987;24:1-10.

110. Votapka TV, Canvasser DA, Pennington DG, Koga M, Swartz MT. Effect of triiodothyronine on graft function in a model of heart transplantation. Ann Thorac Surg 1996;62:78-82.

111. Hing AJ, Hicks M, Garlick SR, Gao L, Kesteven SH, Faddy SC, Wilson MK, Feneley MP, Macdonald PS. The effects of hormone resuscitation on cardiac function and hemodynamics in a porcine brain-dead organ donor model. Am J Transplant 2007;7:809-17.

112. Zimmerman EA, Nilaver G, Hou-Yu A, Silverman AJ. Vasopressinergic and oxytocinergic pathways in the central nervous system. Fed Proc 1984;43:91-6.

113. Yoshioka T, Sugimoto H, Uenishi M, Sakamoto T, Sadamitsu D, Sakano T, Sugimoto T. Prolonged hemodynamic maintenance by the combined administration of vasopressin and epinephrine in brain death: a clinical study. Neurosurgery 1986;18:565-7.

114. Blaine EM, Tallman RD Jr, Frolicher D, Jordan MA, Bluth LL, Howie MB. Vasopressin supplementation in a porcine model of brain-dead potential organ donors. Transplantation 1984;38:459-64.

115. Rostron AJ, Avlonitis VS, Cork DM, Grenade DS, Kirby JA, Dark JH. Hemodynamic resuscitation with arginine vasopressin reduces lung injury after brain death in the transplant donor. Transplantation 2008;85:597-606.

116. Chen JM, Cullinane S, Spanier TB, Artrip JH, John R, Edwards $\mathrm{NM}, \mathrm{Oz}$ MC, Landry DW. Vasopressin deficiency and pressor hypersensitivity in hemodynamically unstable organ donors. Circulation 1999;100:II244-6.

117. Pennefather SH, Bullock RE, Mantle D, Dark JH. Use of low dose arginine vasopressin to support brain-dead organ donors. Transplantation 1995;59:58-62.

118. Kinoshita Y, Yahata K, Yoshioka T, Onishi S, Sugimoto T. Longterm renal preservation after brain death maintained with vasopressin and epinephrine. Transpl Int 1990;3:15-8.

119. Papadopoulos G, Sintou E, Siminelakis S, Koletsis E, Baikoussis NG, Apostolakis E. Perioperative infusion of low- dose of vasopressin for prevention and management of vasodilatory vasoplegic syndrome in patients undergoing coronary artery bypass grafting-A double-blind randomized study. J Cardiothorac Surg 2010;5:17.

120. Calva E, Mújica A, Núñez R, Aoki K, Bisteni A, Sodi-Pallares D. Mitochondrial biochemical changes and glucose-KCl-insulin solution in cardiac infarct. Am J Physiol 1966;211:71-6.

121. Opie LH, Bruyneel K, Owen P. Effects of glucose, insulin and potassium infusion on tissue metabolic changes within first hour of myocardial infarction in the baboon. Circulation 1975;52:49-57.

122. Sodi-pallares D, Testelli MR, Fishleder BL, Bisteni A, Medrano GA, Friedland C, De Micheli A. Effects of an intravenous infusion of a potassium-glucose-insulin solution on the electrocardiographic signs of myocardial infarction. A preliminary clinical report. Am J Cardiol 1962;9:166-81. 
123. Fath-Ordoubadi F, Beatt KJ. Glucose-insulin-potassium therapy for treatment of acute myocardial infarction: an overview of randomized placebo-controlled trials. Circulation 1997;96:1152-6.

124. Sun SC, Appleyard R, Masetti P, Byrne JG, Laurence RG, Marsh JD, Cohn LH. Improved recovery of heart transplants by combined use of oxygen-derived free radical scavengers and energy enhancement. $J$ Thorac Cardiovasc Surg 1992;104:830-7.

125. Pilati CF, Bosso FJ, Maron MB. Factors involved in left ventricular dysfunction after massive sympathetic activation. Am J Physiol 1992;263:H784-91.

126. Szabo G, Buhmann V, Bahrle S, Vahl CF, Hagl S. Brain death impairs coronary endothelial function. Transplantation 2002;73:1846-8.

127. Nicolas-Robin A, Amour J, Ibanez-Esteve C, Coriat P, Riou B, Langeron O. Effect of glucose-insulin-potassium in severe acute heart failure after brain death. Crit Care Med 2008;36:2740-5.

128. Heusch G, Schulz R, Rahimtoola SH. Myocardial hibernation: a delicate balance. Am J Physiol Heart Circ Physiol 2005;288:H984-99.

129. Stanley AW Jr, Moraski RE, Russell RO, Rogers WJ, Mantle JA, Kreisberg RA, McDaniel HG, Rackley CE. Effects of glucose-insulinpotassium on myocardial substrate availability and utilization in stable coronary artery disease. Studies on myocardial carbohydrate, lipid and oxygen arterial-coronary sinus differences in patients with coronary artery disease. Am J Cardiol 1975;36:929-37.

130. Taegtmeyer H, Goodwin GW, Doenst T, Frazier OH. Substrate metabolism as a determinant for postischemic functional recovery of the heart. Am J Cardiol 1997;80: A3-10.

131. Cottin Y, Lhuillier I, Gilson L, Zeller M, Bonnet C, Toulouse C, Louis P, Rochette L, Girard C, Wolf JE. Glucose insulin potassium infusion improves systolic function in patients with chronic ischaemic cardiomyopathy. Eur J Heart Fail 2002;4:181-4.

132. Khoury VK, Haluska B, Prins J, Marwick TH. Effects of glucoseinsulin-potassium infusion on chronic ischaemic left ventricular dysfunction. Heart 2003;89:61-5.

133. Demircan S, Yazici M, Diraman E, Demircan G, Kilicaslan F, Durna K, Acar Z, Eren Z. The effect of glucose-insulin-potassium treatment on myocardial oxidative stress in patients with acute coronary syndromes undergoing percutaneous coronary intervention. Coron Artery Dis 2008;19:99-104.

134. Kalay N, Ozdogru I, Gul A, Yucel Y, Cetinkaya Y, Inanc MT, Dogan A, Kaya MG, Eryol NK. Effects of intermittent and long-term glucoseinsulin-potassium infusion in patients with systolic heart failure. Exp Clin Cardiol 2008;13:85-8.

135. Klein LJ, van Campen CM, Sieswerda GT, Kamp O, Visser FC. Effects of high-dose insulin infusion on left ventricular function in normal subjects. Neth Heart J 2010;18:183-9.

136. Meybohm P, Bein B, Brosteanu O, Cremer J, Gruenewald M, Stoppe C, Coburn M, Schaelte G, Böning A, Niemann B, Roesner J, Kletzin F, Strouhal U, Reyher C, Laufenberg-Feldmann R, Ferner M, Brandes IF, Bauer M, Stehr SN, Kortgen A, Wittmann M, Baumgarten G, Meyer-Treschan T, Kienbaum P, Heringlake M, Schön J, Sander M, Treskatsch S, Smul T, Wolwender E, Schilling T, Fuernau G, Hasenclever D, Zacharowski K; RIPHeart Study Collaborators. A multicenter trial of remote ischaemic preconditioning for heart surgery. N Engl J Med 2015;373:1397-407.

137. Hausenloy DJ, Candilio L, Evans R, Ariti C, Jenkins DP, Kolvekar S, Knight R, Kunst G, Laing C, Nicholas J, Pepper J, Robertson S, Xenou M, Clayton T, Yellon DM; ERICCA Trial Investigators. Remote ischaemic preconditioning and outcomes of cardiac surgery. N Engl J Med 2015;373:1408-17.

138. Przyklenk K, Bauer B, Ovize M, Kloner RA, Whittaker P. Regional ischaemic 'preconditioning' protects remote virgin myocardium from subsequent sustained coronary occlusion. Circulation 1993;87:893-9.

139. Thielmann M, Kottenberg E, Kleinbongard P, Wendt D, Gedik N, Pasa S, Price V, Tsagakis K, Neuhäuser M, Peters J, Jakob H, Heusch G. Cardioprotective and prognostic effects of remote ischaemic preconditioning in patients undergoing coronary artery bypass surgery: a single-centre randomised, double-blind, controlled trial. Lancet 2013;382:597-604.

140. Hong DM, Lee EH, Kim HJ, Min JJ, Chin JH, Choi DK, Bahk JH, Sim JY, Choi IC, Jeon Y. Does remote ischaemic preconditioning with postconditioning improve clinical outcomes of patients undergoing cardiac surgery? Remote ischaemic preconditioning with postconditioning outcome trial. Eur Heart J 2014;35:176-83.

141. Sachdeva J, Dai W, Gerczuk PZ, Kloner RA. Combined remote perconditioning and postconditioning failed to attenuate infarct size and contractile dysfunction in a rat model of coronary artery occlusion. J Cardiovasc Pharmacol Ther 2014;19:567-73.

142. Eitel I, Stiermaier T, Rommel KP, Fuernau G, Sandri M, Mangner N, Linke A, Erbs S, Lurz P, Boudriot E, Mende M, Desch S, Schuler G, Thiele H. Cardioprotection by combined intrahospital remote ischaemic perconditioning and postconditioning in ST-elevation myocardial infarction: the randomized lipsia conditioning trial. Eur Heart J 2015;36:3049-57.

143. Pichot S, Mewton N, Bejan-Angoulvant T, Roubille F, Rioufol G, Giraud C, Boussaha I, Lairez O, Elbaz M, Piot C, Angoulvant D, Ovize M. Influence of cardiovascular risk factors on infarct size and interaction with mechanical ischaemic postconditioning in STelevation myocardial infarction. Open Heart 2015;2:e000175.

144. Moscarelli M, Angelini GD, Suleiman S, Fiorentino F, Punjabi PP. Remote ischaemic preconditioning: is it a flag on the field? Perfusion 2015;30:438-47.

145. Kottenberg E, Musiolik J, Thielmann M, Jakob H, Peters J, Heusch G. Interference of propofol with signal transducer and activator of transcription 5 activation and cardioprotection by remote ischaemic preconditioning during coronary artery bypass grafting. J Thorac Cardiovasc Surg 2014;147:376-82.

146. Kleinbongard P, Neuhäuser M, Thielmann M, Kottenberg E, Peters J, Jakob H, Heusch G. Confounders of cardioprotection by remote ischaemic preconditioning in patients undergoing coronary artery bypass grafting. Cardiology 2016;133:128-33.

147. Hausenloy DJ, Boston-Griffiths EA, Yellon DM. Cyclosporin A and cardioprotection: from investigative tool to therapeutic agent. $\mathrm{Br} J$ Pharmacol 2012;165:1235-45.

148. Hausenloy DJ, Kunst G, Boston-Griffiths E, Kolvekar S, Chaubey S, John L, Desai J, Yellon D. The effect of cyclosporin-A on perioperative myocardial injury in adult patients undergoing coronary artery bypass graft surgery: a randomised controlled clinical trial. Heart 2014;100:544-9.

149. Iyer A, Gao L, Doyle A, Rao P, Jayewardene D, Wan B, Kumarasinghe G, Jabbour A, Hicks M, Jansz PC, Feneley MP, Harvey RP, Graham RM, Dhital KK, Macdonald PS. Increasing the tolerance of DCD hearts to warm ischemia by pharmacological postconditioning. Am J Transplant 2014; 14:1744-52.

150. Watson AJ, Gao L, Sun L, Tsun J, Jabbour A, Ru Qiu M, Jansz PC, Hicks M, Macdonald PS. Enhanced preservation of the rat heart after prolonged hypothermic ischemia with erythropoietin-supplemented Celsior solution. J Heart Lung Transplant 2013;32:633-40.

151. Trahanas JM, Witer LJ, Alghanem F, Bryner BS, Iyengar A, Hirschl JR, Hoenerhoff MJ, Potkay JA, Bartlett RH, Rojas-Pena A, Owens GE, Bocks ML. Achieving 12 hour normothermic ex situ heart perfusion: an experience of 40 porcine hearts. ASAIO J 2016;62:470-6.

152. Hing AJ, Watson A, Hicks M, Gao L, Faddy SC, McMahon AC, Kesteven SH, Wilson MK, Jansz P, Feneley MP, Macdonald PS. Combining cariporide with glyceryl trinitrate optimizes cardiac preservation during porcine heart transplantation. Am J Transplant 2009;9:2048-56.

153. Gao L, Tsun J, Sun L, Kwan J, Watson A, Macdonald PS, Hicks M. Critical role of the STAT3 pathway in the cardioprotective efficacy of zoniporide in a model of myocardial preservation - the rat isolated working heart. Br J Pharmacol 2011;162:633-47. 